\title{
Carbene-metal complexes as molecular scaffolds for construction of through-space TADF emitters
}

\author{
Armands Ruduss, ${ }^{a}$ Baiba Turovska, ${ }^{b}$ Sergey Belyakov, ${ }^{b}$ Kitija A. Stucere, ${ }^{c}$ Aivars Vembris, ${ }^{c}$ \\ Kaspars Traskovskis ${ }^{\mathrm{a}^{*}}$
}

${ }^{\text {a }}$ Faculty of Materials Science and Applied Chemistry, Riga Technical University, P. Valdena Str. 3, LV-1048, Riga, Latvia.

E-mail: kaspars.traskovskis@rtu.lv

${ }^{\mathrm{b}}$ Latvian Institute of Organic Synthesis, Aizkraukles Str. 21, Riga LV-1006, Latvia

${ }^{\mathrm{c}}$ Institute of Solid State Physics, University of Latvia, Kengaraga Str. 8, LV-1063, Riga, Latvia.

\begin{abstract}
Through-space charge transfer $(\mathrm{CT})$ process is observed in $\mathrm{Cu}(\mathrm{I})$ carbene-metal-amide complexes, where conventional imidazole or imidazoline N-heterocyclic (NHC) carbene fragments act as inert linkers and CT proceeds between a metal-bound carbazole donor and a distantly situated carbene-bound phenylsulfonyl acceptor. The resulting electron transfer gives a rise to efficient thermally activated delayed fluorescence (TADF), characterized with high photoluminescence quantum yields ( $\Phi_{\mathrm{PL}}$ up to $90 \%$ ) and radiative rates $\left(\mathrm{k}_{\mathrm{r}}\right)$ up to $3.32 \times 10^{5} \mathrm{~s}^{-}$ ${ }^{1}$. TADF process is aided by fast reverse intersystem crossing (rISC) rates of up to $2.56 \times 10^{7} \mathrm{~s}^{-}$ 1. Such emitters can be considered as hybrids of two existing TADF emitter design strategies, combining low singlet-triplet energy gaps $\left(\Delta \mathrm{E}_{\mathrm{ST}}\right)$ met in all-organic exciplex-like emitters $(0.0062-0.0075 \mathrm{eV})$ and small, but non-negligible spin-orbital coupling (SOC) provided by $\mathrm{Cu}$ atom, like in TADF-active organometallic complexes.
\end{abstract}




\section{Introduction}

High cost and rarity of transition metals (Ir, Pt, Os and Re) commonly used for synthesis of triplet emitters have fueled large research interest in alternative structural approaches. Among those, metal-free organic compounds exhibiting thermally activated delayed fluorescence (TADF) have received the most attention. ${ }^{1,2}$ Beside the main focus for applications in organic light emitting diodes (OLEDs), these compounds have found an extensive use in photocatalysis ${ }^{3}$ and time-resolved imaging. ${ }^{4}$ The emission from triplet state in these materials is realized through a reverse intersystem crossing (rISC) process between $T_{1}$ and $S_{1}$ levels, provided that singlet-triplet energy gap $\left(\Delta \mathrm{E}_{\mathrm{ST}}\right)$ is sufficiently small to be overcome at room temperature. The chemical composition of TADF emitters involves a presence of electron donating (D) and accepting (A) structural fragments, between which the emissive charge-transfer $(\mathrm{CT})$ process takes place. Small $\Delta \mathrm{E}_{\mathrm{ST}}$ in these compounds is achieved by minimizing the overlap between HOMO and LUMO wavefunctions, usually confined on D and A moieties. ${ }^{5}$ The majority of the studied structural examples feature D-A pairs that are coupled through $\pi$-conjugated bridging fragments, between which orbital overlap-reducing conformational twists are introduced. The necessity for covalent bonding can be abandoned, by applying physical mixtures of D and A components, which form TADF-active exciplexes with ultralow $\Delta E_{S T}$ values $(<0.001 \mathrm{eV}) .{ }^{6-8}$ Such systems, however, often suffer from poor photoluminescence quantum yields $\left(\Phi_{\mathrm{PL}}\right)$ and wide emission bands due to highly randomized packing patterns of the constituting compounds. The next evolutionary step of TADF emitters introduced so called intramolecular exciplexes, where through-space CT proceeds between covalently bound D and A fragments and through-bond electronic coupling is prevented by $\sigma$ bonding or multiple conformational twists. ${ }^{9-11}$ While such conformationally rigid materials solve some of the previously mentioned issues, the SOC between ${ }^{1} \mathrm{CT}$ and ${ }^{3} \mathrm{CT}$ states is practically nonexistent due to almost identical orbital configurations and the attainment of a rapid spin flip is often reliant on the aid of closely located local excited triplet states $\left({ }^{3} \mathrm{LE}\right) .{ }^{12}$ Hence through-space TADF emitters often suffer from low radiative rates $\left(\mathrm{k}_{\mathrm{r}}\right){ }^{13}$

Organometallic complexes bearing the relatively abundant $\mathrm{Cu}$ metal atom is a conceptually different class of low-cost TADF emitters. ${ }^{14,15}$ While this element does not provide large enough SOC for fast room-temperature phosphorescence, the values are sufficient enough to promote a rapid TADF, despite the considerable $\Delta \mathrm{E}_{\mathrm{ST}}$ gaps met in such compounds $(>0.05 \mathrm{eV})$. Recently a new type of highly emissive materials has arisen among 
this compound class. Exhibiting strongly coupled CT transitions between metal-bound electrophilic carbene and electron-rich amide ligands, these compounds are often referred to as “carbene-metal-amides" (CMAs). ${ }^{16,17}$ Due to a favorable electronic level configuration and metal involvement TADF lifetimes below $1.0 \mu$ s can be achieved. ${ }^{18,19}$

Here we present a novel approach towards TADF emitters that can be considered as a hybrid case between the previously discussed all-organic through-space and metal-assisted designs (Fig. 1). Similarly to the existing CMA emitters, $\mathrm{Cu}$ complexes bearing carbazolide and carbene ligands were synthesized. Imidazole-based N-heterocyclic carbenes (NHCs) were used, with electron-accepting sulfonyl groups introduced at 4-position of the N-bound 2,6diisopropylphenyl (Dipp) substituents (Scheme 1). The strong electron accepting nature of sulfonyls relocates LUMO from the carbene to the perpendicularly aligned Dipp rings, giving a rise to a through-space $\mathrm{CT}$ process with the HOMO-hosting carbazolide fragment. The resulting compounds $\mathbf{1 - 4}$ exhibit unique photophysical behavior, combining low $\Delta \mathrm{E}_{\text {ST }}(0.006$ $\mathrm{eV}$ ) with small, but non-negligible $\mathrm{SOC}$ due to the presence of $\mathrm{Cu}$ atom. These structural examples demonstrate a new design strategy for the development of TADF emitters.

(a) Through-space CT approach

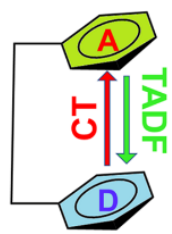

$\Delta \mathrm{E}_{\mathrm{ST}}<0.001 \mathrm{eV}$ $\mathrm{SOC}_{\mathrm{T} 1 / \mathrm{S} 1}=0$ (b) Metal-promoted approach

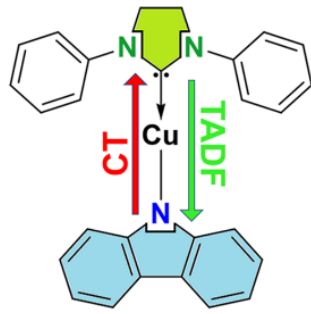

$\Delta \mathrm{E}_{\mathrm{ST}}>0.03 \mathrm{eV}$ $\mathrm{SOC}_{\mathrm{T} 1 / \mathrm{S} 1}>0$ (c) Metal-promoted

through-space CT approach

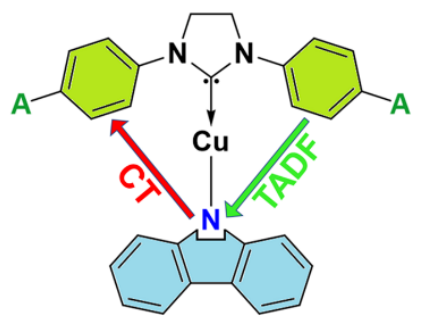

$\Delta \mathrm{E}_{\mathrm{ST}}<0.007 \mathrm{eV}$ $\mathrm{SOC}_{\mathrm{T} 1 / \mathrm{S1}}>0$

Figure 1. Schematic representation of TADF emitter architectures featuring allorganic through space CT (a), metal promoted (b) and our presented hybrid (c) approaches. 

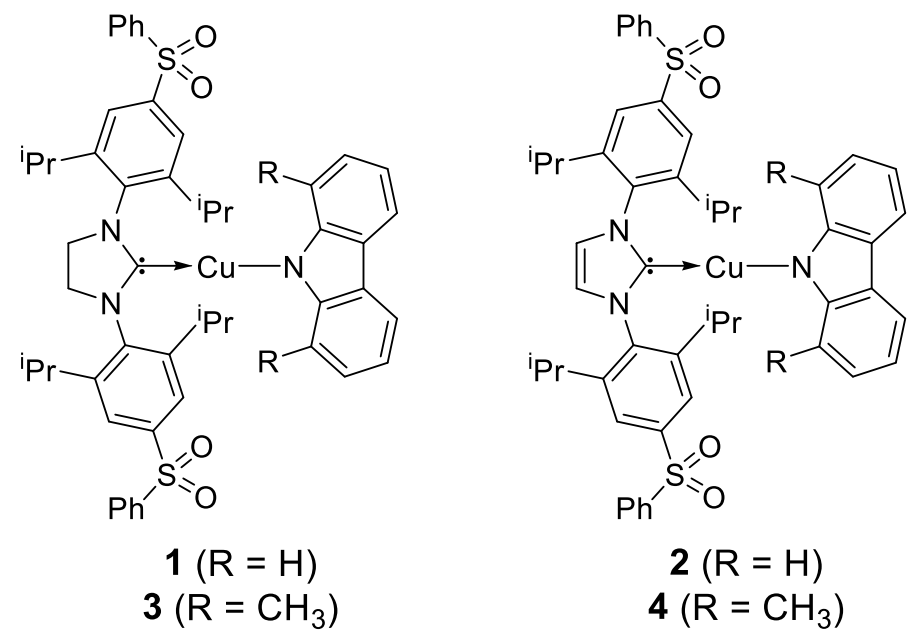

Scheme 1. Chemical structures of CMA complexes 1-4.

\section{Experimental section}

\section{Synthesis and characterization}

All procedures involving synthesis and purification of NHC derivatives were carried out using Schlenk technique. Solvents were dried using standard procedures. Unless specified further, the used materials and solvents were purchased from commercial suppliers. Starting compounds $5, \mathbf{9}^{20}$ and 1,8-dimethylcarbazole ${ }^{21}$ were prepared by following the procedures described in literature. NMR spectra were obtained on a Bruker Avance $300 \mathrm{MHz}$ spectrometer using DMSO- $d 6$ residual signals as an internal reference $\left({ }^{1} \mathrm{H}, \delta 2.50 ;{ }^{13} \mathrm{C}, \delta 39.52\right)$. Elemental analysis was performed using Costech Instruments ECS 4010 CHNS-O Elemental Combustion System. Differential scanning calorimetry (DSC) thermograms were acquired using a Mettler Toledo DSC-1/200 W apparatus at a scanning rate of $10{ }^{\circ} \mathrm{C} \mathrm{min}{ }^{-1}$. Decomposition temperatures were obtained using a PerkinElmer STA 6000 thermal analyzer.

\section{1,3-Bis(2,6-diisopropyl-4-(phenylsulfonyl)phenyl)-4,5-dihydro-1H-imidazol-3-ium}

acetate (6). A solution of 1,3-bis(2,6-diisopropyl-4-(phenylthio)phenyl)-4,5-dihydro-1Himidazol-3-ium chloride (5) $(5.70 \mathrm{~g}, 8.86 \mathrm{mmol})$ and $30 \% \mathrm{H}_{2} \mathrm{O}_{2}(14,0 \mathrm{ml})$ in acetic acid (120 ml) was stirred at $90{ }^{\circ} \mathrm{C}$ for 4 days. The mixture was cooled to room temperature and volatiles were evaporated under reduced pressure. The obtained solid was dispersed in diethyl ether and collected by filtration to afford the product as a white solid. Yield: 5,92 $\mathrm{g}(91 \%) .{ }^{1} \mathrm{H} \mathrm{NMR} \delta_{\mathrm{H}}$ (DMSO-d6, 300 MHz): 9.60 (s, 1H, N=CH-N), 8.13 (d, J = 7.3 Hz, 4H, o-ArH(Ph)), 7.95 (s, 4H, m-ArH(dipp)), $7.77-7.61(\mathrm{~m}, 6 \mathrm{H}, \operatorname{ArH}(\mathrm{Ph})), 4.56$ (s, 4H, CH $\left.2-\mathbf{C H}_{2}\right), 3.12$ (hept, J = 6.6 
$\left.\mathrm{Hz}, 4 \mathrm{H}, \mathrm{CH}\left(\mathrm{CH}_{3}\right)_{2}\right), 1.90$ (s, 3H, $\left.\mathrm{CH}_{3} \mathrm{COO}\right), 1.35$ (d, J = 6.4 Hz, 12H, $\left.\mathrm{CH}\left(\mathrm{CH}_{3}\right)_{2}\right), 1.28$ (d, J = $\left.6.6 \mathrm{~Hz}, 12 \mathrm{H}, \mathrm{CH}\left(\mathrm{CH}_{3}\right)_{2}\right) .{ }^{13} \mathrm{C} \mathrm{NMR} \delta_{\mathrm{C}}(\mathrm{DMSO}-d 6,75.47 \mathrm{MHz}): 172.01\left(\mathrm{CH}_{3} \mathrm{COO}\right), 159.84$ $(\mathrm{N}=\mathrm{CH}-\mathrm{N}), 148.74,143.98,140.42,134.25,134.04,129.96,127.83,123.72,53.86\left(\mathrm{CH}_{2}-\right.$ $\left.\mathbf{C H}_{2}\right), 28.60\left(\mathbf{C H}\left(\mathrm{CH}_{3}\right)_{2}\right), 24.59\left(\mathrm{CH}\left(\mathrm{CH}_{3}\right)_{2}\right), 22.96\left(\mathrm{CH}\left(\mathrm{CH}_{3}\right)_{2}\right), 21.17\left(\mathrm{CH}_{3} \mathrm{COO}\right)$.

1,3-Bis(2,6-diisopropyl-4-(phenylsulfonyl)phenyl)-1H-imidazol-3-ium chloride (10). A solution of 1,3-bis(2,6-diisopropyl-4-(phenylthio)phenyl)-1H-imidazol-3-ium chloride (9) $(4.01 \mathrm{~g}, 6.25 \mathrm{mmol})$, potassium peroxymonosulfate (oxone) $(18.00 \mathrm{~g}, 118.26 \mathrm{mmol})$ in a mixture of methanol $(70 \mathrm{ml})$ and water $(30 \mathrm{ml})$ was stirred at $60{ }^{\circ} \mathrm{C}$ for 16 hours. Then the mixture was cooled to room temperature and filtered. The inorganic solids were washed with an excess of acetone. Volatiles were evaporated from the filtrate under reduced pressure and the resulting mixture was extracted with DCM (3 x $100 \mathrm{ml})$. The extract was dried over $\mathrm{Na}_{2} \mathrm{SO}_{4}$, filtered and evaporated under reduced pressure. The obtained solid was dispersed in diethyl ether and collected by filtration to afford the product as a white solid. Yield: $3.81 \mathrm{~g}(86 \%) .1 \mathrm{H}$ NMR $\delta_{\mathrm{H}}(\mathrm{DMSO}-d 6,300 \mathrm{MHz}): 10.12(\mathrm{~s}, 1 \mathrm{H}, \mathrm{N}=\mathrm{CH}-\mathrm{N}), 8.58(\mathrm{~s}, 2 \mathrm{H}, \mathrm{CH}=\mathrm{CH}), 8.17$ (d, J = $7.2 \mathrm{~Hz}, 4 \mathrm{H}, \mathrm{o}-\mathrm{ArH}(\mathrm{Ph})), 8.05$ (s, 4H m-ArH(dipp)), 7.77 - 7.61 (m, 6H, $\mathrm{ArH}(\mathrm{Ph})), 2.34$ (hept, $\mathrm{J}=6.2 \mathrm{~Hz}, 4 \mathrm{H}), 1.25\left(\mathrm{~d}, J=6.1 \mathrm{~Hz}, 12 \mathrm{H}, \mathrm{CH}\left(\mathrm{CH}_{3}\right)_{2}\right), 1.14\left(\mathrm{~d}, \mathrm{~J}=6.2 \mathrm{~Hz}, 12 \mathrm{H}, \mathrm{CH}\left(\mathrm{CH}_{3}\right)_{2}\right)$. ${ }^{13} \mathrm{C}$ NMR $\delta_{\mathrm{C}}$ (DMSO-d6, 75.47 MHz): 147.72, 144.89, 140.31, 138.93, 134.44, 133.93, 130.06, 127.98, 126.24, 123.56, $29.15\left(\mathrm{CH}\left(\mathrm{CH}_{3}\right)_{2}\right), 23.72\left(\mathrm{CH}\left(\mathrm{CH}_{3}\right)_{2}\right), 22.73\left(\mathrm{CH}\left(\mathrm{CH}_{3}\right)_{2}\right)$.

Compound 7. A mixture of 6 (4.00 g, $5.47 \mathrm{mmol})$ and $\mathrm{Ag}_{2} \mathrm{O}(1.33 \mathrm{~g}, 5.73 \mathrm{mmol})$ in acetonitrile $(200 \mathrm{ml})$ was stirred for 1 hour in room temperature. The mixture was filtered through a pad of Celite and filtrate was evaporated under reduced pressure. The product was purified via column chromatography (silica gel, eluent: DCM to DCM/methanol, 100/5). Volatiles were evaporated under reduced pressure to afford the product as white solid. An analytical sample was purified via crystallization from dioxane. Yield: $2.39 \mathrm{~g}(52 \%)$. ${ }^{1} \mathrm{H}$ NMR $\delta_{\mathrm{H}}(\mathrm{DMSO}-d 6,300 \mathrm{MHz}): 8.08$ (d, J = 7.1 Hz, 4H, o-ArH(Ph)), 7.86 (s, 4H, m-ArH(dipp)), 7.75 - 7.59 (m, 6H, $\operatorname{ArH}(\mathrm{Ph})$ ), 4.12 (s, 4H, CH2-CH2), 3.10 (hept, J = 6.5 Hz, 4H, CH(CH$)_{2}$ ), $1.54\left(\mathrm{~s}, 3 \mathrm{H}, \mathrm{CH}_{3} \mathrm{COO}\right), 1.34-1.20\left(\mathrm{~m}, 24 \mathrm{H}, \mathrm{CH}\left(\mathrm{CH}_{3}\right)_{2}\right) .{ }^{13} \mathrm{C}$ NMR $\delta_{\mathrm{C}}(\mathrm{DMSO}-d 6,75.47$ MHz): $205.48\left(\mathrm{dd}, \mathrm{J}_{\mathrm{C}-109 \mathrm{Ag}}=266 \mathrm{~Hz} ; \mathrm{J}_{\mathrm{C}-107 \mathrm{Ag}}=230 \mathrm{~Hz}, \mathbf{C}-\mathrm{Ag}\right), 175.31\left(\mathrm{CH}_{3} \mathrm{COO}\right), 149.12$, 142.33, 140.81, 139.29, 133.99, 129.88, 127.63, $123.51,53.69$ (d, J-Ag $=8.5 \mathrm{~Hz}, \mathbf{C H}_{2}-\mathbf{C H}_{2}$ ), $28.49\left(\mathrm{CH}\left(\mathrm{CH}_{3}\right)_{2}\right), 24.64\left(\mathrm{CH}\left(\mathrm{CH}_{3}\right)_{2}\right), 23.27\left(\mathrm{CH}\left(\mathrm{CH}_{3}\right)_{2}\right), 22.39\left(\mathrm{CH}_{3} \mathrm{COO}\right)$.

Compound 11. A mixture of $\mathbf{1 0}(1.45 \mathrm{~g}, 2.06 \mathrm{mmol})$ and $\mathrm{Ag}_{2} \mathrm{O}(1.43 \mathrm{~g}, 6.17 \mathrm{mmol})$ in acetonitrile $(60 \mathrm{ml})$ was stirred for 1 hour in room temperature. The mixture was filtered through a pad of Celite and filtrate was evaporated under reduced pressure. The product was purified via column chromatography (silica gel, eluent: DCM to DCM/methanol, 100/4). 
Volatiles were evaporated under reduced pressure to afford product as white solid. Yield: 0.77 g (46\%). ${ }^{1} \mathrm{H}$ NMR $\delta_{\mathrm{H}}(\mathrm{DMSO}-d 6,300 \mathrm{MHz}): 8.15$ (d, J = 7.0 Hz, 4H, o-ArH(Ph)), 8.10 (s, 2H, $\mathrm{CH}=\mathrm{CH}), 7.95$ (s, 4H, m-ArH(dipp)), $7.77-7.63(\mathrm{~m}, 6 \mathrm{H}, \operatorname{ArH}(\mathrm{Ph})), 2.52-2.41$ (m, 4H, $\left.\mathrm{CH}\left(\mathrm{CH}_{3}\right)_{2}\right), 1.25-1.12\left(\mathrm{~m}, 24 \mathrm{H}, \mathrm{CH}\left(\mathrm{CH}_{3}\right)_{2}\right) .{ }^{13} \mathrm{C}$ NMR $\delta_{\mathrm{C}}(\mathrm{DMSO}-d 6,75.47 \mathrm{MHz}): 181.86$ $\left(\mathrm{dd}, \mathrm{J}_{\mathrm{C}-109 \mathrm{Ag}}=265 \mathrm{~Hz} ; \mathrm{J}_{\mathrm{C}-107 \mathrm{Ag}}=230 \mathrm{~Hz}, \mathbf{C}-\mathrm{Ag}\right), 147.72,143.37,140.65,138.53,134.13$, 129.92, 127.76, $124.96\left(\mathrm{~d}, \mathrm{~J}_{\mathrm{C}-\mathrm{Ag}}=6.5 \mathrm{~Hz}, \mathbf{C H}=\mathbf{C H}\right), 123.17,28.70\left(\mathbf{C H}\left(\mathrm{CH}_{3}\right)_{2}\right), 23.74$ $\left(\mathrm{CH}\left(\mathrm{CH}_{3}\right)_{2}\right), 23.04\left(\mathrm{CH}\left(\mathrm{CH}_{3}\right)_{2}\right)$.

Compound 8. A mixture of $7(1.50 \mathrm{~g}, 1.84 \mathrm{mmol})$ and $\mathrm{CuBr}(0.80 \mathrm{~g}, 5.58 \mathrm{mmol})$ in dry DCM (40 ml) was stirred for 16 hours in room temperature. The mixture was filtered through a pad of Celite and filtrate was evaporated under reduced pressure. The product was purified via column chromatography (silica gel, eluent: DCM/methanol, 100/1). Volatiles were evaporated under reduced pressure to afford product as white solid. Yield: $1.09 \mathrm{~g}(73 \%) .{ }^{1} \mathrm{H}$ NMR $\delta_{\mathrm{H}}(\mathrm{DMSO}-d 6,300 \mathrm{MHz}): 8.07(\mathrm{~d}, \mathrm{~J}=7.1 \mathrm{~Hz}, 4 \mathrm{H}, o-\operatorname{ArH}(\mathrm{Ph})), 7.86\left(\mathrm{~s}, 4 \mathrm{H}, \mathrm{m}^{-}\right.$ $\operatorname{ArH}(\operatorname{dipp})), 7.75-7.59$ (m, 6H, $\operatorname{ArH}(\mathrm{Ph})$ ), 4.07 (s, 4H, CH2-CH2), 3.11 (hept, J = 6.7 Hz, 4H, $\left.\mathrm{CH}\left(\mathrm{CH}_{3}\right)_{2}\right), 1.32-1.22\left(\mathrm{~m}, 24 \mathrm{H}, \mathrm{CH}\left(\mathrm{CH}_{3}\right)_{2}\right) .{ }^{13} \mathrm{C}$ NMR $\delta_{\mathrm{C}}(\mathrm{DMSO}-d 6,75.47 \mathrm{MHz}): 201.32$ (C-Cu), 149.09, 142.28, 140.85, 138.96, 133.99, 129.89, 127.59, 123.41, $53.50\left(\mathbf{C H}_{2}-\mathbf{C H}_{2}\right)$, $28.49\left(\mathbf{C H}\left(\mathrm{CH}_{3}\right)_{2}\right), 24.75\left(\mathrm{CH}\left(\mathrm{CH}_{3}\right)_{2}\right), 23.15\left(\mathrm{CH}\left(\mathrm{CH}_{3}\right)_{2}\right)$.

Compound 12. A mixture of $11(0.40 \mathrm{~g}, 0.49 \mathrm{mmol})$ and $\mathrm{CuBr}(0.14 \mathrm{~g}, 0.98 \mathrm{mmol})$ in dry DCM $(20 \mathrm{ml})$ was stirred for 72 hours. The mixture was filtered through a pad of Celite. The filtrate was collected and DCM was evaporated under reduced pressure to afford product as white solid of sufficient purity for further reactions. Yield: $0.38 \mathrm{~g}(96 \%) .{ }^{1} \mathrm{H}$ NMR $\delta_{\mathrm{H}}$ (DMSO-d6, $300 \mathrm{MHz}$ ): 8.15 (d, J = 7.0 Hz, 4H, o-ArH(Ph)), 7.97 (s, 2H, CH=CH), 7.95 (s, $4 \mathrm{H}, m-\operatorname{ArH}(\operatorname{dipp})), 7.77-7.62(\mathrm{~m}, 6 \mathrm{H}, \operatorname{ArH}(\mathrm{Ph})), 2.54-2.42\left(\mathrm{~m}, 4 \mathrm{H}, \mathrm{CH}\left(\mathrm{CH}_{3}\right)_{2}\right), 1.23-1.15$ $\left(\mathrm{m}, 24 \mathrm{H}, \mathrm{CH}\left(\mathrm{CH}_{3}\right)_{2}\right) .{ }^{13} \mathrm{C}$ NMR $\delta_{\mathrm{C}}(\mathrm{DMSO}-d 6,75.47 \mathrm{MHz}): 178.16(\mathbf{C}-\mathrm{Cu}), 147.71,143.25$, $140.68,138.38,134.13,129.93,127.74,124.45,123.07,28.73\left(\mathbf{C H}\left(\mathrm{CH}_{3}\right)_{2}\right), 23.85\left(\mathrm{CH}\left(\mathrm{CH}_{3}\right)_{2}\right)$, $22.92\left(\mathrm{CH}\left(\mathrm{CH}_{3}\right)_{2}\right)$.

General method for synthesis of complexes 1 - 4. All the operations involving the synthesis and purification of NHC-Cu-Cbz complexes were carried out using dry, deoxygenated solvents (THF, hexane and diethyl ether). Carbazole (or 1,8-dimethylcarbazole) and $\mathrm{KOtBu}$ or $\mathrm{NaH}$ was dissolved in THF and stirred for 30 minutes under argon atmosphere. Then a THF solution of NHC-CuBr was added dropwise via syringe to the solution of carbazole amide. The resulting mixture was stirred for 3 hours under argon atmosphere and then filtered through a pad of Celite into hexane (approx. $100 \mathrm{ml}$ ) to precipitate the product. The mixture was filtered and the solid was washed with diethyl ether to afford product. 
Complex 1. General procedure: A solution of carbazole $(0.130 \mathrm{~g}, 0.78 \mathrm{mmol})$ and $\mathrm{NaH}$ (0.032 g, $0.80 \mathrm{mmol}, 60 \%$ dispersion in mineral oil) in THF (5 ml) and a solution of $8(0.30 \mathrm{~g}$, $0.37 \mathrm{mmol})$ in THF (10 ml). Yield: $0.22 \mathrm{~g}(63 \%)$, white solid. ${ }^{1} \mathrm{H}$ NMR $\delta_{\mathrm{H}}$ (DMSO-d6, 300 MHz): 8.20 (d, $J=7.4 \mathrm{~Hz}, 4 \mathrm{H}, o-\operatorname{ArH}(\mathrm{Ph})), 8,04$ (s, 4H, m-ArH(dipp)), $7.82-7.65$ (m, 8H, $\left.\operatorname{ArH}(\mathrm{Ph}), \mathrm{CH}^{4}(\mathrm{Cbz})\right), 6.66\left(\mathrm{t}, \mathrm{J}=7.3 \mathrm{~Hz}, 2 \mathrm{H}, \mathrm{CH}^{2}(\mathrm{Cbz})\right), 6.44\left(\mathrm{t}, \mathrm{J}=7.6 \mathrm{~Hz}, 2 \mathrm{H}, \mathrm{CH}^{3}(\mathrm{Cbz})\right)$, $5.65\left(\mathrm{~d}, \mathrm{~J}=8.1 \mathrm{~Hz}, 2 \mathrm{H}, \mathrm{CH}^{1}(\mathrm{Cbz})\right), 4.26\left(\mathrm{~s}, 4 \mathrm{H}, \mathrm{CH}_{2}-\mathrm{CH}_{2}\right), 3.32-3.20\left(\mathrm{~m}, 4 \mathrm{H}, \mathrm{CH}\left(\mathrm{CH}_{3}\right)_{2}\right)$, $1.36\left(\mathrm{~d}, \mathrm{~J}=6.7 \mathrm{~Hz}, 12 \mathrm{H}, \mathrm{CH}\left(\mathrm{CH}_{3}\right)_{2}\right), 1.21\left(\mathrm{~d}, \mathrm{~J}=6.7 \mathrm{~Hz}, 12 \mathrm{H}, \mathrm{CH}\left(\mathrm{CH}_{3}\right)_{2}\right) .{ }^{13} \mathrm{C} \mathrm{NMR} \delta_{\mathrm{C}}$ (DMSO-d6, 75.47 MHz): 201.89 (NCN), 149.63, 148.84, 143.01, 141.00, 139.12, 134.06, 130.00, 127.80, 123.68, 123.27, 119.03, 115.18, 112.97, $53.65\left(\mathrm{CH}_{2}-\mathbf{C H}_{2}\right), 28.67\left(\mathbf{C H}\left(\mathrm{CH}_{3}\right)_{2}\right)$, $24.72\left(\mathrm{CH}\left(\mathrm{CH}_{3}\right)_{2}\right), 23.17\left(\mathrm{CH}\left(\mathrm{CH}_{3}\right)_{2}\right)$. Elemental analysis calculated for $\mathrm{C}_{51} \mathrm{H}_{54} \mathrm{CuN}_{3} \mathrm{O}_{4} \mathrm{~S}_{2}: \mathrm{C}$, 68.01; H, 6.04; N, 4.67. Found: C, 68.06; H, 5.97; N, 4.60.

Complex 2. General procedure: A solution of carbazole $(0.123 \mathrm{~g}, 0.74 \mathrm{mmol})$ and $\mathrm{KOtBu}(0.088 \mathrm{~g}, 0.78 \mathrm{mmol})$ in THF $(5 \mathrm{ml})$ and a solution of $12(0.30 \mathrm{~g}, 0.37 \mathrm{mmol})$ in THF (15 ml). Yield: $0.31 \mathrm{~g}$ (93\%), white solid. ${ }^{1} \mathrm{H}$ NMR $\delta_{\mathrm{H}}$ (DMSO-d6, $\left.300 \mathrm{MHz}\right): 8.27-8.18$ (m, $6 \mathrm{H}, o-\operatorname{ArH}(\mathrm{Ph}), \mathrm{CH}=\mathrm{CH}), 8.12$ (s, 4H, m-ArH(dipp)), 7.83 - 7.66 (m, 8H, $\operatorname{ArH}(\mathrm{Ph})$, $\left.\mathrm{CH}^{4}(\mathrm{Cbz})\right), 6.72\left(\mathrm{t}, \mathrm{J}=7.3 \mathrm{~Hz}, 2 \mathrm{H}, \mathrm{CH}^{2}(\mathrm{Cbz})\right), 6.56\left(\mathrm{t}, \mathrm{J}=7.4 \mathrm{~Hz}, 2 \mathrm{H}, \mathrm{CH}^{3}(\mathrm{Cbz})\right), 5.88$ (d, J $=8.1 \mathrm{~Hz}, 2 \mathrm{H}, \mathrm{CH}^{1}(\mathrm{Cbz})$ ), 2.61 (hept, $\left.\mathrm{J}=6.5 \mathrm{~Hz}, 4 \mathrm{H}, \mathrm{CH}\left(\mathrm{CH}_{3}\right)_{2}\right), 1.26(\mathrm{~d}, \mathrm{~J}=6.7 \mathrm{~Hz}, 12 \mathrm{H}$, $\left.\mathrm{CH}\left(\mathrm{CH}_{3}\right)_{2}\right), 1.19\left(\mathrm{~d}, \mathrm{~J}=6.7 \mathrm{~Hz}, 12 \mathrm{H}, \mathrm{CH}\left(\mathrm{CH}_{3}\right)_{2}\right) .{ }^{13} \mathrm{C}$ NMR $\delta_{\mathrm{C}}(\mathrm{DMSO}-d 6,75.47 \mathrm{MHz})$ $178.87(\mathrm{NCN}), 148.93,148.14,143.82,140.85,138.54,134.16,130.01,127.86,124.61$, 123.32, 119.13, 115.21, 113.00, $28.95\left(\mathbf{C H}\left(\mathrm{CH}_{3}\right)_{2}\right), 23.90\left(\mathrm{CH}\left(\mathrm{CH}_{3}\right)_{2}\right), 22.98\left(\mathrm{CH}\left(\mathrm{CH}_{3}\right)_{2}\right)$. Elemental analysis calculated for $\mathrm{C}_{51} \mathrm{H}_{52} \mathrm{CuN}_{3} \mathrm{O}_{4} \mathrm{~S}_{2}$ : C, 68.16; H, 5.83; N, 4.68. Found: C, $67.97 ; \mathrm{H}, 6.11 ; \mathrm{N}, 4.62$.

Complex 3. General procedure: A solution of 1,8-dimethylcarbazole $(0.082 \mathrm{~g}, 0.42$ $\mathrm{mmol})$ and KOtBu (0.048 g, $0.43 \mathrm{mmol})$ in THF (5 ml) and a solution of $8(0.25 \mathrm{~g}, 0.31 \mathrm{mmol})$ in THF (10 ml). Compound was recrystallized from chlorobenzene. Yield: $0.21 \mathrm{~g} \mathrm{(73 \% ),} \mathrm{white}$ solid. ${ }^{1} \mathrm{H}$ NMR $\delta_{\mathrm{H}}(\mathrm{DMSO}-d 6,300 \mathrm{MHz}): 8.18(\mathrm{~d}, J=7.4 \mathrm{~Hz}, 4 \mathrm{H}, o-\operatorname{ArH}(\mathrm{Ph})), 7.94(\mathrm{~s}, 4 \mathrm{H}$, $m$-ArH(dipp)), 7.85 - 7.67 (m, 6H, ArH(Ph)), 7.57 (d, J = 7.5 Hz, 2H, CH²(Cbz)), 6.61 (t, J = $\left.7.3 \mathrm{~Hz}, 2 \mathrm{H}, \mathrm{CH}^{3}(\mathrm{Cbz})\right), 6.13$ (d, J=7.0 Hz, 2H, CH${ }^{1}(\mathrm{Cbz})$ ), 4.11 (s, 4H, CH2-CHz), 3.19 (hept, $\left.\mathrm{J}=6.6 \mathrm{~Hz}, 4 \mathrm{H}, \mathrm{CH}\left(\mathrm{CH}_{3}\right)_{2}\right), 1.32\left(\mathrm{~d}, \mathrm{~J}=6.7 \mathrm{~Hz}, 12 \mathrm{H}, \mathrm{CH}\left(\mathrm{CH}_{3}\right)_{2}\right), 1.16-1.07(\mathrm{~m}, 18 \mathrm{H}$, $\left.\mathrm{CH}\left(\mathrm{CH}_{3}\right)_{2}, \mathrm{CH}_{3}(\mathrm{Cbz})\right) .{ }^{13} \mathrm{C} \mathrm{NMR} \delta_{\mathrm{C}}(\mathrm{DMSO}-d 6,75.47 \mathrm{MHz}): 201.36(\mathrm{NCN}), 148.75,148.17$, $142.71,140.89$, 139.73, 134.06, 129.96, 127.83, 124.17, 124.04, 123.68, 121.03, 116.50, 115.26, $54.03\left(\mathrm{CH}_{2}-\mathrm{CH}_{2}\right), 28.59\left(\mathrm{CH}\left(\mathrm{CH}_{3}\right)_{2}\right), 24.00\left(\mathrm{CH}\left(\mathrm{CH}_{3}\right)_{2}\right), 23.78\left(\mathrm{CH}\left(\mathrm{CH}_{3}\right)_{2}\right), 18.10$ $\left(\mathrm{CH}_{3}(\mathrm{Cbz})\right)$. Elemental analysis calculated for $\mathrm{C}_{53} \mathrm{H}_{58} \mathrm{CuN}_{3} \mathrm{O}_{4} \mathrm{~S}_{2}: \mathrm{C}, 68.54 ; \mathrm{H}, 6.29 ; \mathrm{N}, 4.52$. Found: C, 68.50; H, 6.08; N, 3.96. 
Complex 4. General procedure: A solution of 1,8-dimethylcarbazole $(0.078 \mathrm{~g}, 0.40$ $\mathrm{mmol})$ and $\mathrm{KOtBu}(0.045 \mathrm{~g}, 0.40 \mathrm{mmol})$ in THF $(5 \mathrm{ml})$ and a solution of $\mathbf{1 2}(0.25 \mathrm{~g}, 0.31 \mathrm{mmol})$ in THF (10 ml). Yield: $0.26 \mathrm{~g} \mathrm{(91 \% ),} \mathrm{white} \mathrm{solid.}{ }^{1} \mathrm{H}$ NMR $\delta_{\mathrm{H}}$ (DMSO-d6, $\left.300 \mathrm{MHz}\right): 8.24$ (d, $J=7.4 \mathrm{~Hz}, 4 \mathrm{H}, o-\operatorname{ArH}(\mathrm{Ph})), 8.12$ (s, 2H, CH=CH), 8.04 (s, 4H, m-ArH(dipp)), $7.87-7.71$ (m, 6H, $\operatorname{ArH}(\mathrm{Ph})), 7.61\left(\mathrm{~d}, \mathrm{~J}=7.5 \mathrm{~Hz}, 2 \mathrm{H}, \mathrm{CH}^{2}(\mathrm{Cbz})\right), 6.65\left(\mathrm{t}, \mathrm{J}=7.3 \mathrm{~Hz}, 2 \mathrm{H}, \mathrm{CH}^{3}(\mathrm{Cbz})\right), 6.20$ $\left(\mathrm{d}, J=6.9 \mathrm{~Hz}, 2 \mathrm{H}, \mathrm{CH}^{1}(\mathrm{Cbz}), 2.64\right.$ (hept, J = 6.7 Hz, 4H, CH$\left.\left(\mathrm{CH}_{3}\right)_{2}\right), 1.29-1.19$ (m, 18H, $\left.\mathrm{CH}\left(\mathrm{CH}_{3}\right)_{2}, \mathrm{CH}_{3}(\mathrm{Cbz})\right), 1.11\left(\mathrm{~d}, \mathrm{~J}=6.7 \mathrm{~Hz}, 12 \mathrm{H}, \mathrm{CH}\left(\mathrm{CH}_{3}\right)_{2}\right) .{ }^{13} \mathrm{C}$ NMR $\delta_{\mathrm{C}}(\mathrm{DMSO}-d 6,75.47$ MHz): 177.63 (NCN), 148.12, 147.56, 143.64, 140.75, 139.06, 134.23, 130.04, 127.95, 125.21, 123.99, 123.82, 120.83, 116.64, 115.26, $28.84\left(\mathrm{CH}\left(\mathrm{CH}_{3}\right)_{2}\right), 23.36\left(\mathrm{CH}\left(\mathrm{CH}_{3}\right)_{2}\right), 23.34$ $\left(\mathrm{CH}\left(\mathrm{CH}_{3}\right)_{2}\right), 18.34\left(\mathrm{CH}_{3}(\mathrm{Cbz})\right)$. Elemental analysis calculated for $\mathrm{C}_{53} \mathrm{H}_{56} \mathrm{CuN}_{3} \mathrm{O}_{4} \mathrm{~S}_{2}: \mathrm{C}, 68.69$; H, 6.09; N, 4.53. Found: C, 68.42; H, 6.18; N, 4.60.

\section{X-ray Crystallography}

Suitable monocrystals of $\mathbf{1}$ were prepared by slow liquid-liquid diffusion between THF solution and diethyl ether. For $\mathbf{4}$ a slow evaporation of chlorobenzene solution was employed. Crystallographic diffraction data for 1, 4 (orthorhombic form) and 4 (monoclinic form) were collected with a Rigaku, XtaLAB Synergy, Dualflex, HyPix diffractometer $\left(\mathrm{Cu}-\mathrm{K}_{\alpha}, \lambda=\right.$ $1.54184 \AA$ ) equipped with a low temperature Oxford Cryosystems Cryostream Plus device. The crystal structures were solved by direct methods with the ShelXT ${ }^{22}$ structure solution program using intrinsic phasing and refined with the SHELXL refinement package. ${ }^{23}$ All calculations were performed with Olex 2 software. ${ }^{24}$ Table S1 lists the main crystal data for these compounds. Crystallographic data for 1, 4 (orthorhombic form) and $\mathbf{4}$ (monoclinic form) are deposited at the Cambridge Crystallographic Data Centre as supplementary publications CCDC 2047368, 2047337 and 2047338. Copies of the data can be obtained, free of charge, on application to CCDC, 12 Union Road, Cambridge CB2 1EZ, UK.

\section{Cyclic Voltammetry Measurements}

Cyclic voltammetry measurements were performed with PARSTAT 2273 potentiostat. Electrochemical redox reactions were examined in $0.1 \mathrm{M}$ tetra butylammonium hexafluorophosphate $\left(\mathrm{TBAPF}_{6}\right)$ solutions in anhydrous acetonitrile under Ar atmosphere. The measurements were carried out using a three-electrode cell configuration. Stationary glassy 
carbon disk $(\varnothing 0.5 \mathrm{~cm})$ was used as a working electrode, Pt wire - as an auxiliary electrode. Potentials were measured vs Ag wire electrode.

\section{Photo physical measurements}

Optical measurements were carried in solutions with typical material concentrations of $1-2 \cdot 10^{-4} \mathrm{~mol} \mathrm{~L}^{-1}$. Solutions for $\Phi_{\mathrm{PL}}$ and emission decay measurements were prepared in glovebox under Ar atmosphere using previously degassed solvents. PMMA films for optical measurements were prepared from chlorobenzene solutions $(30 \mathrm{mg} / \mathrm{mL}$ material concentration) using drop-casting method. After the deposition of the solution on glass slides the samples were immediately placed in preheated oven and dried for 2 hours at $80^{\circ} \mathrm{C}$. The UV-Vis spectra were recorded with a Perkin Elmer Lambda 35 spectrometer. Depending on the nature of the experiment, photoluminescence properties were measured on two different spectroscopic systems. Emission spectra, $\Phi_{\mathrm{PL}}$ and PL lifetimes for solution and thin films at room temperature, as well as PL spectra, time-resolved measurements and PL lifetimes at $77 \mathrm{~K}$ (in liquid nitrogen filled quartz Dewar) were measured with QuantaMaster 40 spectrofluorometer (Photon Technology International, Inc.). The $375 \mathrm{~nm}$ laser with 60 ps pulse width and tunable repetition rate (between $1 \mathrm{Mh}$ and $50 \mathrm{kHz}$ ) was used for the fast (nanosecond - microsecond range) kinetics measurements. Steady state and pulsed ( $3 \mu$ s pulse width) xenon lamp was used for steady state and millisecond kinetics measurements. The excitation source for temperaturedependent (10-300 K) photoluminescence measurements in helium cryostat was a tunable Ekspla laser NT 342/3UV with the repetition rate $10 \mathrm{~Hz}$ and $5 \mathrm{~ns}$ pulse width. Photoluminescence spectra and PL decays were obtained with PMT attached to Andor monochromator.

Low temperature $\Phi_{\mathrm{PL}}$ data were acquired by integrating the corresponding PL intensities and calibrating the values using $\Phi_{\mathrm{PL}}$ data acquired at room temperature. ${ }^{8}$ In order to correctly analyze CT emission and avoid the possible contribution of carbazolide ${ }^{3} \mathrm{LE}$ phosphorescence, only the CT emission was accounted for, when estimating low-temperature $\Phi_{\mathrm{PL}}$ values. To do so, the PL intensities were collected in time-resolved mode, till the point, where the collected CT emission intensity did not show any further increase and no apparent contribution from ${ }^{3} \mathrm{LE}$ was detectable in a form of an overlapping structured emission band. The examples of such measurements conducted for $\mathbf{2}$ and $\mathbf{4}$ at $60 \mathrm{~K}$ temperature are shown in Fig. S1. 


\section{Quantum chemical calculations}

Density functional theory (DFT) calculations for geometry optimization and timedependent DFT (TD-DFT) calculations for excited state energies were performed using Schrödinger Jaguar ${ }^{25}$ software package (release 2020-2). Geometry optimization and TD-DFT calculations employed MN15 ${ }^{26}$ functional and LACVP** basis. Tamm-Dancoff approximation (TDA) was used for TD-DFT. Based on symmetrical X-ray structures of $\mathbf{1}$ and 4, $\mathrm{C}_{\mathrm{S}}$ symmetry was set for the structures during the optimization. Conductor-like polarizable continuum model (CPCM) was used to account for solvation effects. Specifically, benzene ( $\varepsilon$ $=2.27$ ) was chosen for TD-DFT calculations to closer simulate the media polarity in PMMA films $(\varepsilon=3.9) .{ }^{27}$ Molecular orbital overlap integrals and $\mathrm{Cu}$ atom contribution to orbitals (Becke method) were calculated with Multiwfn ${ }^{28}$ program. $T_{1}$ geometries of $\mathbf{1}$ and $\mathbf{4}$ were obtained via spin-unrestricted SCF calculations. The attempts to obtain $\mathrm{S}_{1}$ geometry were not successful, due to the tendency of TD-DFT method to limit the distance between through-space CT constituting carbazolide and Dipp ring systems, resulting in the breakage of the complex structure. SOC values and phosphorescence rates for 1 were calculated with ADF program. ${ }^{29}$ Perturbative SOC (pSOC) TD-DFT method was used with TZP basis and MN15 functional.

\section{OLED preparation and characterization}

The necessary materials, poly(3,4-ethylenedioxythiophene) polystyrene sulfonate (PEDOT:PSS) as hole injection material, poly(N,N'-bis-4-butylphenyl-N,N'bisphenyl)benzidine (polyTPD) as a hole transport material, 9-(4-tert-butylphenyl)-3,6bis(triphenylsilyl)-9H-carbazole (CzSi) as a host and 2,2',2' -(1,3,5-benzinetriyl)-tris(1phenyl-1-H-benzimi-dazole) (TPBi) as an electron transport material were purchased from Ossila and used as received.

Electroluminescent devices with the structure ITO/PEDOT:PSS/PolyTPD/ 4: $\mathrm{CzSi} / \mathrm{TPBi} / \mathrm{LiF} / \mathrm{Al}$ were fabricated in an inert atmosphere. ITO-coated glass with a sheet resistance of $15 \Omega / \mathrm{sq}$ was used. Hole injection, hole transport and emitting layers were deposited by spin-coating on pre-patterned ITO-coated glass substrates. For the emitting layer chlorobenzene was used as the solvent. Electron transport, injection and metal layers were subsequently deposited by thermal evaporation in vacuum. Deposition was performed at the pressure lover than $2 \times 10^{-6} \mathrm{mBar}$. Each sample contained 6 pixels with the size of $16 \mathrm{~mm}^{2}$. The current-voltage characteristics of the OLEDs were measured with Keithley 2450 SourceMeter. 
The electroluminescence brightness was measured with Konica Minolta Luminance and Color Meter CS-150. Electroluminescence (EL) spectra were taken by the OceanOptics STS-VIS spectrometer.

\section{Results and Discussion}

\section{Synthesis and structure}

Sulfone-functionalized N,N'-bis(2,6-diisopropylphenyl)imidazol)-2-ylidene and N,N'bis(2,6-diisopropylphenyl)-4,5-dihydroimidazol)-2-ylidene carbene precursors $\mathbf{6}$ and $\mathbf{1 0}$ were acquired following a previously reported synthetic route for 2,6-dimethylphenyl-substituted structural analogues (Scheme 2). ${ }^{20} \mathrm{NHC}-\mathrm{Ag}(\mathrm{I})$ complexes 7 and $\mathbf{1 1}$ were obtained by reaction between imidazolium or imidazolinium salts and $\mathrm{Ag}_{2} \mathrm{O}$. Transmetallation in the presence of $\mathrm{CuBr}$ and subsequent reaction with deprotonated carbazole $(\mathrm{Cbz})$ or 1,8-dimethylcarbazole (MeCbz) afforded CMA complexes 1-4 as off-white crystalline solids. The detailed synthetic procedures are provided in the Supporting Information. In the crystalline form the compounds are stable and can be stored indefinitely under air exposure. The decomposition temperatures of the complexes vary in the range of $300-315^{\circ} \mathrm{C}$ (Fig. S2). 

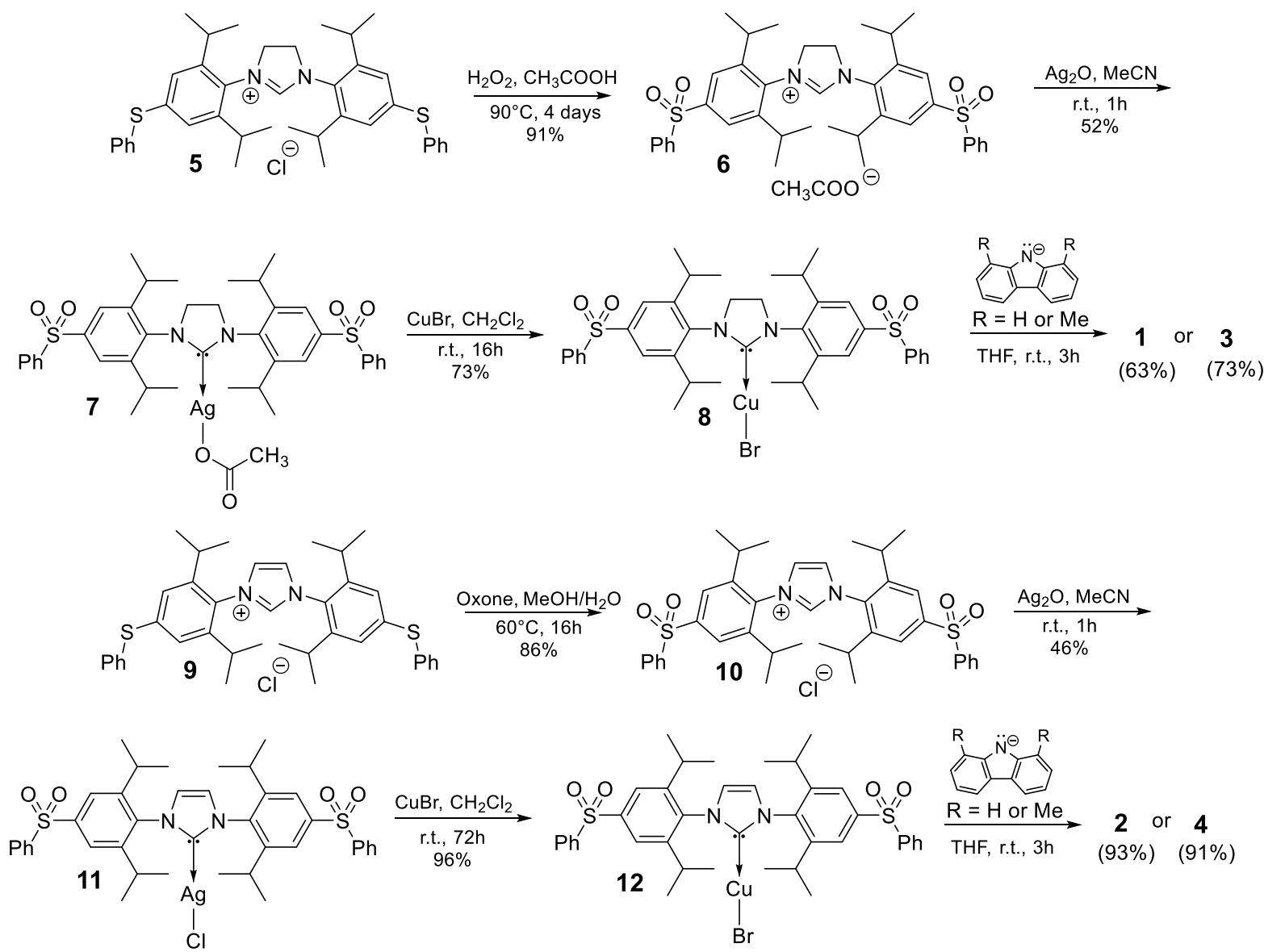

Scheme 2. Synthetic route of CMA complexes 1-4.

X-ray diffraction analysis was successfully performed for compounds 1 and 4 (Fig. 2). As it is evident from the acquired X-ray structures, the geometry of the complexes is largely affected by the structure of the attached carbazolide ligand. Complex $\mathbf{1}$ exhibits a nearly linear geometry with a slight bending at $\mathrm{Cu}\left(\angle \mathrm{C} 1-\mathrm{Cu}-\mathrm{N} 2=182.3^{\circ}\right)$ and $\mathrm{N} 2(\angle \mathrm{Cu}-\mathrm{N} 2-" \mathrm{Cbz}$ centroid" $\left.=177.7^{\circ}\right)$. The lengths of metal-ligand bonds, $\mathrm{C} 1-\mathrm{Cu}(1.857 \AA)$ and $\mathrm{Cu}-\mathrm{N} 2(1.841 \AA)$, are slightly shorter than in the previously reported structural analogue $\operatorname{IPr}-\mathrm{Cu}-\mathrm{Cz}$ featuring unfunctionalized Dipp rings (1.874 and $1.877 \AA),{ }^{30}$ thus indicating a slightly stronger bonding. The alignment between $\mathrm{Cbz}$ and imidazole planes is coplanar, in contrast to $\operatorname{IPr}-\mathrm{Cu}-\mathrm{Cz}$, where these planes assume a perpendicular configuration. With the introduction of bulkier MeCbz ligand in 4, a steric repulsion between Dipp ring and MeCbz methyls takes place and the linearity of the axis $\mathrm{C} 1-\mathrm{Cu}-" \mathrm{Cbz}$ centroid" cannot be retained. The structural strain in $\mathbf{4}$ is mainly relieved by the bending at MeCbz nitrogen $\left(\angle \mathrm{Cu}-\mathrm{N} 2-" \mathrm{Cbz}\right.$ centroid" $\left.=147.3^{\circ}\right)$. This process can be related to a formal hybridization change of the carbazolide nitrogen from the typical $\mathrm{sp}^{2}$ to the $\mathrm{sp}^{3}$-like state, as indicated by the apparent structural pyramidalization at $\mathrm{N} 2$ atom and by the carbazolide N2-C2 bond lengthening, from 1.374 to $1.406 \AA$. The release of 
the sterical strain by the $90^{\circ}$ rotation of the carbazolide plane, like in several other reported CMAs, ${ }^{17,30,31}$ in this case is not possible due to the repulsion between the carbazolide methyls and the isopropyl groups of two Dipp fragments. In comparison to complex $\mathbf{1}$, the interligand bridge in 4 (C1-Cu-N2) is slightly extended (by $0.081 \AA$ ).
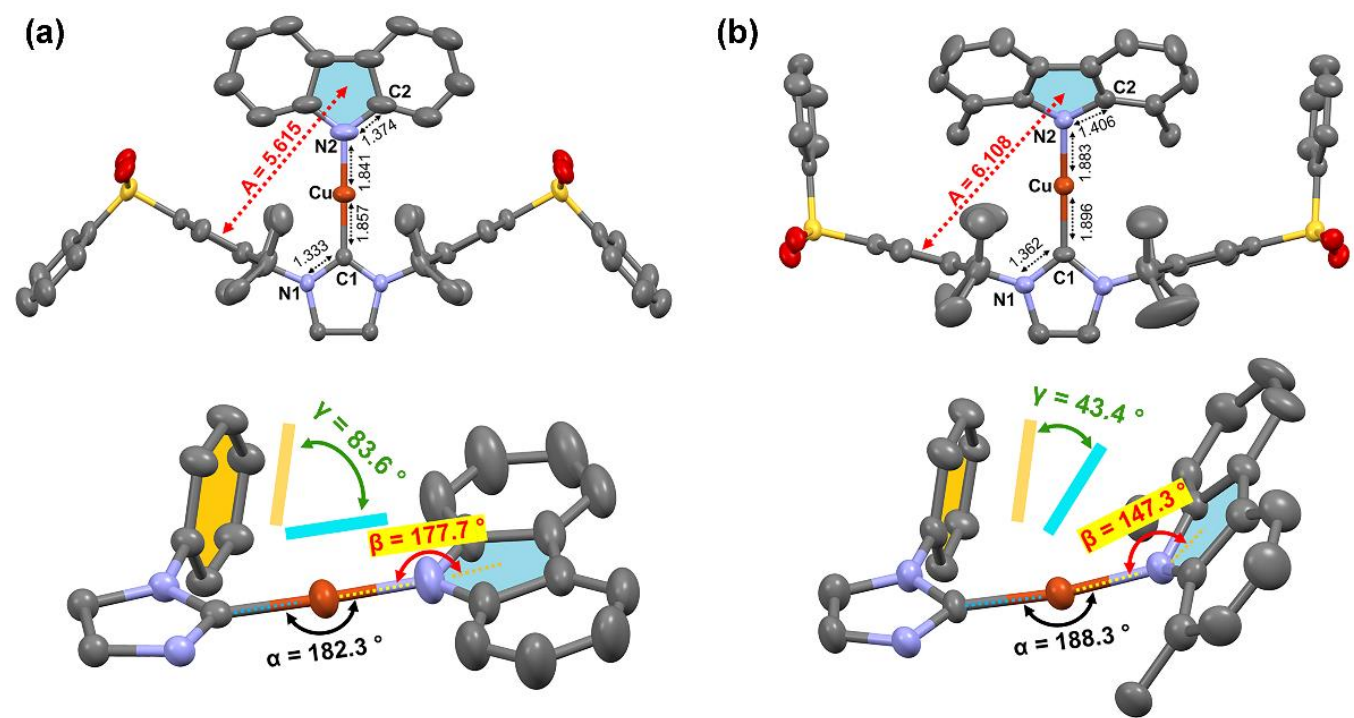

Figure 2. Top and side views of crystal X-ray structures for 1 (a) and monoclinic form of 4 (b). Thermal ellipsoids are drawn at the $50 \%$ probability level. Hydrogen atoms and solvent molecules are omitted for clarity. Only one of the two independent molecules in unit cell are shown for 4. Bond lengths are given in $\AA$. Distance A is measured between centroids of carbazolide 5-membered ring and Dipp, while $\gamma$ illustrates the dihedral angle between the planes of the corresponding rings.

Temperature-induced polymorphism is observed for the studied monocrystal of $\mathbf{4}$. At room temperature conditions the crystal assumes a stable orthorhombic form, while cooling causes a phase transition to a monoclinic polymorph. The temperature dependence of crystal lattice parameters is outlined in Table S2, indicating that the phase transition proceeds at 219 $\mathrm{K}$ (Fig. S3). This process is also evident by low-temperature differential scanning calorimetry (DSC) measurements (Fig. S4). It should be noted that the change from the orthorhombic form to the monoclinic occurs without the destruction of the single crystals and X-ray structures of both forms were obtained. Thus, a typical second-order phase transition is observed.

\section{Electrochemistry}

The cyclic voltammetry measurements in acetonitrile solutions were conducted to examine electrochemical properties of the complexes (Fig. S5, Table S3). All compounds show 
similar voltammetry traces. Oxidation potentials $\left(E_{o x}\right)$ vary in a narrow range from -0.06 to $0.01 \mathrm{~V}$ and are assigned to an electron transfer at carbazolide ligands. ${ }^{32}$ In contrast to Cbzfunctionalized structural analogues, identical anodic shift of about $0.04 \mathrm{~V}$ can be observed for MeCbz-bearing compounds $\mathbf{3}$ and $\mathbf{4}$, thus indicating a similar electronic configuration that arises due to the sterical overcrowding-induced structural changes. A larger dispersity is observed among the reduction potentials $\left(\mathrm{E}_{\mathrm{red}}\right)$. Cathodic shift of about $0.15 \mathrm{~V}$ is measured for compounds $\mathbf{1}$ and $\mathbf{2}$ in comparison to $\mathbf{3}$ and $\mathbf{4}$. The fact that this $\mathrm{E}_{\text {red }}$ difference cannot be related to the structure of imidazoline or imidazole-based carbene fragments, but again, can be correlated to the attached carbazolide structures, allows us to assume that the observed reduction process is related to electrochemical processes at the metal. This is also indicated by the low electrochemical bandgap. Such electrochemical behavior is common for $\mathrm{Cu}(\mathrm{I})$ complexes, for which voltammetry cannot be used to reliably determine LUMO energy levels. ${ }^{33,34}$ Accordingly, ferrocene/ferrocenium redox couple was used as the reference to convert $\mathrm{E}_{\mathrm{ox}}$ into HOMO, while the LUMO value was subsequently estimated with the use of experimental optical bandgap values (Table S3).

\section{Computational analysis}

An understanding about the molecular orbital configuration for $\mathbf{1 - 4}$ is provided by the Density Functional Theory (DFT) calculations. The theoretical investigations were performed at the MN15/LACVP** level. ${ }^{26}$ In a similar fashion to the known CMAs, HOMO is predominantly situated on the carbazolide, with a small $(5.8-6.1 \%)$ contribution of the metal atom (Fig. 3a, S6; Table S4). ${ }^{18,35,36}$ LUMO, on the other hand, shows a contrasting behavior. This frontier orbital is relocated from the NHC-ring to the electron deficient diphenylsulfone groups. Because of the orthogonal configuration, LUMO is completely separated from the carbene-forming ring. This creates several distinctions from the previously reported CMAs. First, the calculated LUMOs have negligible metal contribution, in the range of $0.5-0.8 \%$. For the compounds that host LUMO directly on the carbene moiety these values usually reach a considerable level of 7-22 \% ${ }^{18,35-37}$ Second, relatively to the HOMO-hosting carbazolide, LUMO has now been shifted to a more distant molecular region. Consequently, very small HOMO-LUMO overlap integrals of (0.05-0.08) are calculated for the synthesized structures (Table S3). For CMAs with LUMO-hosting carbene rings this parameter usually exceeds 0.26 , as the frontier orbitals are placed closer and share a common metal atom. ${ }^{35,36}$ 
(a)

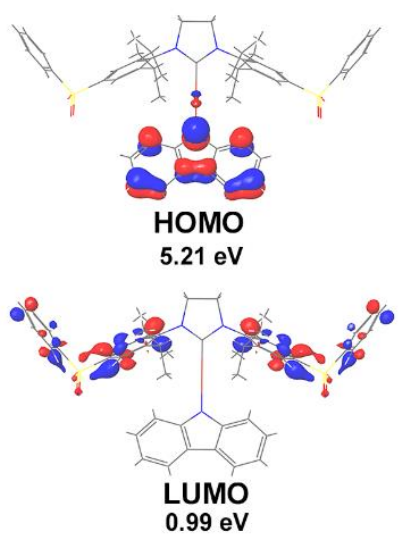

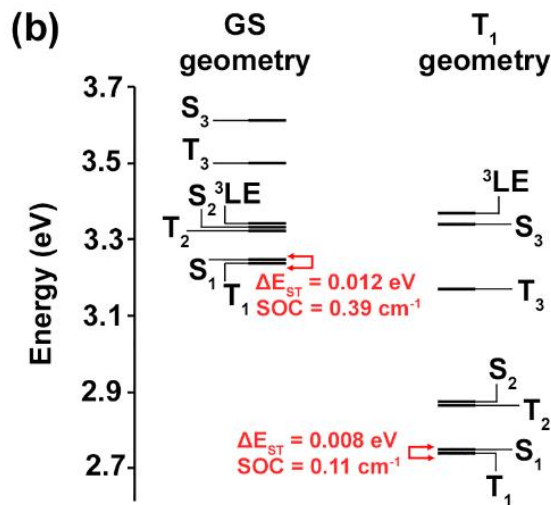

(c)

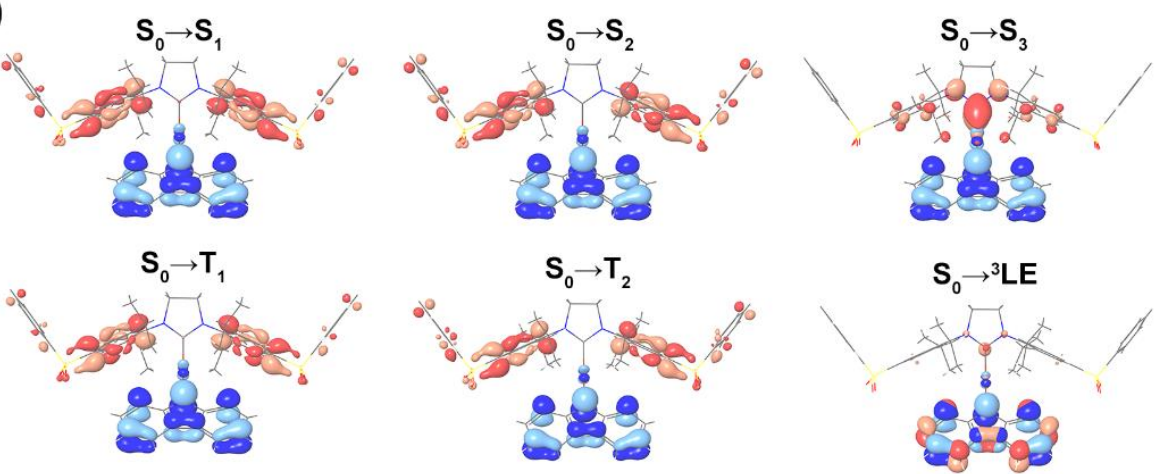

Figure 3. HOMO and LUMO orbitals (a), energy level diagram for the lowest energy excited states (b) and the corresponding natural transition orbitals (NTOs) (c) for complex 1. Blue NTOs correspond to a hole, but red to a particle.

Time-dependent DFT (TD-DFT) calculations were performed to predict the nature and energy level configuration of the excited states of the complexes (Fig. 3b; Table S5). At the ground state (GS) geometry the lowest energy singlet transition $\left(S_{0} \rightarrow S_{1}\right)$ in $\mathbf{1}-\mathbf{4}$ has a throughspace interligand CT character and proceeds with an electron transfer between the frontier orbital pair located on carbazolide and the Dipp rings (Fig. 3c, S7). Through-bond electron transfer between the involved molecular fragments in this case is prevented by both, the presence of the bridging metal atom and the orthogonal twist between NHC and diphenylsulfone planes. Consequently, the predicted $\mathrm{S}_{0} \rightarrow \mathrm{S}_{1}$ transitions show relatively small oscillator strength values in the range of 0.0027-0.0058. Among the investigated structures the oscillator strength of the $\mathrm{S}_{0} \rightarrow \mathrm{S}_{1}$ transition is around 1.5-2 times higher for of MeCbzcontaining compounds 3 and $\mathbf{4}$. The extent of the electronic coupling in through-space charge transfer chromophores is affected by the spatial alignment of donor and acceptor aromatic ring systems, and face-to-face configuration leads to a much stronger coupling than edge-to-face arrangement. ${ }^{38}$ As evident by the obtained X-ray (Fig. 2) and DFT-optimized structures, the 
dihedral angle between $\mathrm{Cbz}$ and Dipp planes $(\gamma)$ becomes substantially smaller, if $\mathrm{MeCbz}$ ligand is present (in $\mathbf{3}$ and $\mathbf{4}$ ) due to the sterical strain induced bending of the carbazolide plane.

Because of a complete spatial separation of the frontier molecular orbitals the predicted energy gaps between $S_{1}$ and $T_{1}$ states are low $(0.007-0.021 \mathrm{eV}$; Table S5). To evaluate the heavy metal effect on the potential enhancement of ISC and rISC rates, SOC values between $S_{1}$ and $T_{1}$ states were calculated for complex 1 . Despite the practically identical orbital configuration, a non-zero SOC value of $0.39 \mathrm{~cm}^{-1}$ is predicted at GS geometry. Because $\mathrm{Cu}$ atom has practically no contribution to LUMO, the corresponding SOC is by approximately two orders of magnitude lower than the values typical for CMAs with carbazolide-to-NHC CT states. ${ }^{39}$ Nevertheless, the calculated SOC value can be considered as sufficient to promote a rapid TADF, taking into account the low $\Delta \mathrm{E}_{\mathrm{ST}}$ values. ${ }^{40} \mathrm{~T}_{1}$ excited state geometries were obtained for $\mathbf{1}$ and $\mathbf{4}$. No major structural changes are observed in comparison to GS, except for a slight planarization at $\mathrm{C} 1-\mathrm{Cu}-\mathrm{N} 2$ axis, indicating a decreased sterical strain. The excited state configuration at $\mathrm{T}_{1}$ geometry is almost identical to that of GS, with lower excitations being carbazolide-to-Dipp CT states and with no major changes in $\triangle \mathrm{E}_{\mathrm{ST}}$ and SOC values.

\section{Photophysical properties}

UV-Vis absorption spectra of complexes $\mathbf{1 - 4}$ in toluene are shown in Fig. 4a. In analogy to other CMAs, the structured bands at $300-380 \mathrm{~nm}$ interval can be attributed to the ${ }^{1} \pi \pi *$ transitions of carbazolide ligands. ${ }^{32}$ The lowest energy edge of the carbazolide absorption partly overlaps with weaker intensity bands that extend up to $450 \mathrm{~nm}$ mark. These spectral features show extinction coefficients in the range of $1000-3000 \mathrm{M}^{-1} \mathrm{~cm}^{-1}$ and exhibit a hypsochromic shift with increasing solvent polarity (Fig. 4b). Negative solvatochromism designates the interligand CT nature of the corresponding transitions. Theoretical and experimental investigations of CMAs have related such CT-band property to the inversion in molecular dipole direction upon the photoexcitation. ${ }^{17,41,42}$ 

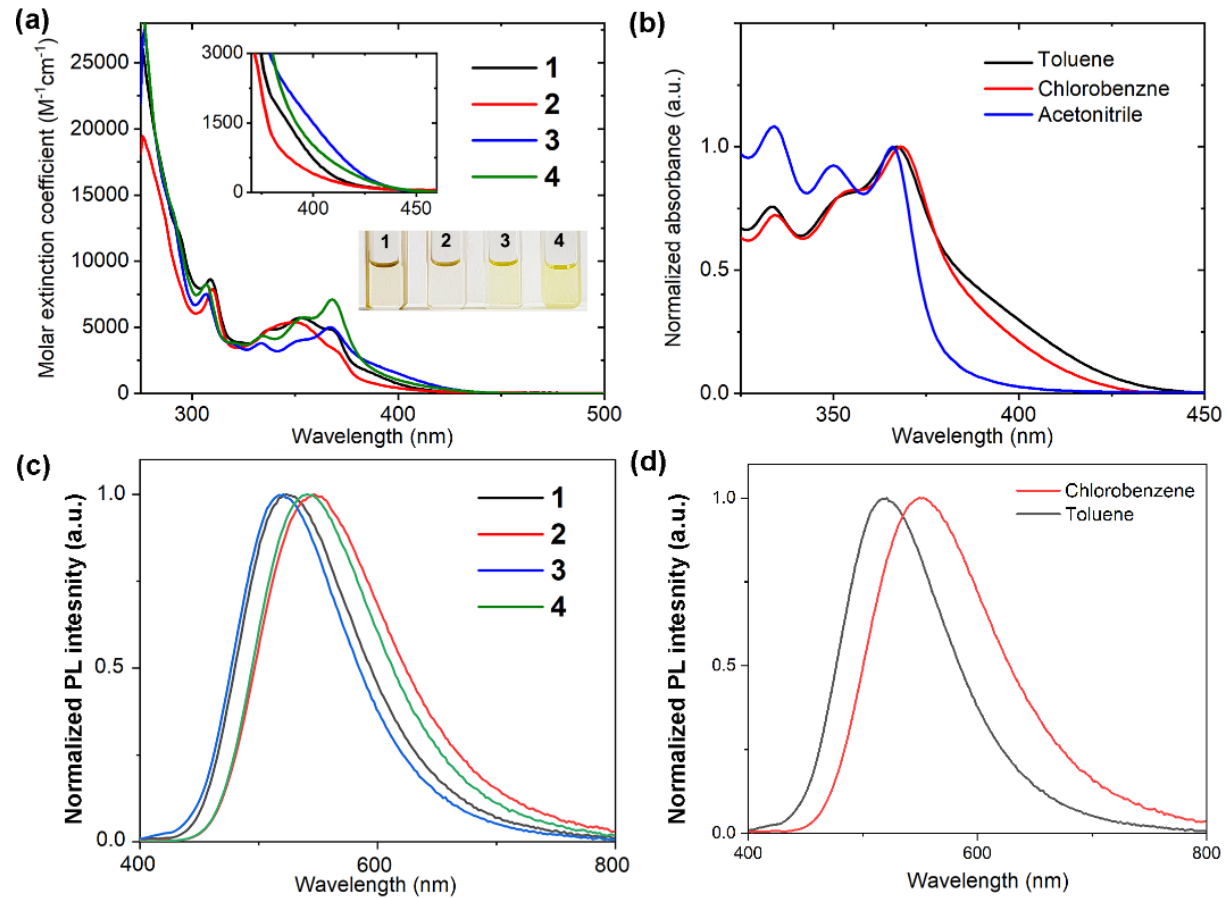

Figure 4. (a) UV-Vis absorption spectra of complexes 1-4 in toluene solution. Inset shows magnified CT absorption bands, while photograph - the corresponding solutions. (b) Transformation of CT band of $\mathbf{3}$ in solvents with varied polarity $\left(\varepsilon_{\mathrm{tol}}=2.38\right.$; $\varepsilon_{\text {chlorobenz. }}=5.62$; $\left.\varepsilon_{\mathrm{ACN}}=37.5\right)$. (c) PL bands of 1-4 in toluene. (d) PL bands of complex $\mathbf{3}$ in various solvents.

A correlation between the intensity of CT absorption bands and the structure of the complexed carbazolide can be made. For the MeCbz-containing complexes $\mathbf{3}$ and $\mathbf{4}$ extinction coefficients are by a factor of 2 larger (Fig. 4a, inset), giving the corresponding solutions a yellowish tint, whereas the solutions of Cbz-containing compounds $\mathbf{1}$ and $\mathbf{2}$ are practically colorless. This is in agreement with TD-DFT predictions, which designate larger oscillator strength values for $\mathbf{3}$ and $\mathbf{4}$ due to the increased coplanarity between the aromatic rings involved in the through-space CT process.

The results of photoluminescence (PL) measurements in toluene solutions are outlined in Table S6. All compounds show wide and featureless emission bands with maxima at 521-547 nm (Fig. 4c), indicating CT character of the emissive excited states. This is a contrasting behavior to IPr-Cu-Cz and some other related structural analogues, which show structured emission bands due to the phosphorescence from ${ }^{3} \mathrm{LE}$ states. ${ }^{30,31}$ In agreement with the theoretical predictions, which reveal more stabilized lowest energy CT states for imidazoline-based complexes 2 and 4, these compounds show bathochromic PL shifts of 20-24 $\mathrm{nm}$. The PL bands exhibit a characteristic positive solvatochromism, which arises due to the ${ }^{1} \mathrm{CT}$ state stabilization by the solvation shell, as evident by the emission spectra in toluene and 
chlorobenzene (Fig. 4d, S8). ${ }^{32}$ With further solvent polarity increase (e.g. acetonitrile) the complexes become non-emissive. The emission efficiency of compounds in the dissolved state is relatively low. Among the screened solvents the highest $\Phi_{\mathrm{PL}}$ values are measured in toluene $(0.21-0.31)$. As indicated by the rapid non-radiative decay rates $\left(\mathrm{k}_{\mathrm{nr}}\right)$, PL efficiency of $\mathbf{1}-\mathbf{4}$ in fluid media is strongly affected by a vibrational relaxation. This can be related to the structural specifics of the complexes. Namely, two possible torsional motions can disrupt the emissive donor-acceptor system: the rotation around the carbazolide-metal $\left(\mathrm{N}_{\mathrm{Cbz}}-\mathrm{Cu}\right)$ and carbene-Dipp $\left(\mathrm{N}_{\text {Carb }}-\mathrm{C}_{\text {Dipp }}\right)$ bonds.

Similarly to several other through-space CT emitters, ${ }^{10,43}$ PL efficiency of $\mathbf{1}-\mathbf{4}$ substantially increases, when compounds are dispersed in solid matrix, as the torsional degree of freedom in the molecules is reduced. In doped PMMA films (5 wt $\%$ emitter content) all compounds possess large $\Phi_{\mathrm{PL}}$ values in the range of $0.84-0.90$ (Table 1). Complexes are susceptible to a strong concentration quenching and in the neat films $\Phi_{\mathrm{PL}}$ drops to $0.03-0.08$. We note that this is a contrasting behavior to the previously reported CMAs possessing carbazolide-to-NHC CT states, which are able to retain relatively high quantum yields even in pure form. ${ }^{32}$ This difference can be related to the fact that for the CT states involving NHC ring the bulky side groups act as buffer, preventing close contacts between the emissive regions of the molecule, whether for 1-4 CT proceeds with the involvement of the peripheral fragments, allowing more pronounced emission quenching. The investigated samples experience notable PL intensity drop, when exposed to oxygen, affirming that the mechanism of the emissive processes involves excited triplet states (Fig. S9). Characteristically for through-space CT emitters, the measured PL bands are wide, with maxima in $472-492 \mathrm{~nm}$ interval (Fig. 5a).

Table 1. Emissive properties of complexes 1-4. Measurements taken in doped PMMA films with emitter concentration $5 \mathrm{wt} \%$.

\begin{tabular}{|c|c|c|c|c|c|c|c|c|c|c|c|c|c|}
\hline Complex & $\begin{array}{c}\lambda_{\max }, \\
\mathrm{nm}\end{array}$ & $\Phi_{P L}$ & $\begin{array}{c}\tau_{\text {prompt }}, \\
\text { ns }\end{array}$ & $\tau_{T A D F^{I}}, \mu \mathrm{s}$ & $\tau_{T A D F^{2}}, \mu \mathrm{s}$ & $\begin{array}{l}k_{r_{\text {prompt }},}, \\
\times 10^{5} \mathrm{~s}^{-1}\end{array}$ & $\begin{array}{l}k_{r_{T A D F 1},} \\
\times 10^{5} \mathrm{~s}^{-1}\end{array}$ & $\begin{array}{l}k_{r_{T A D F 1}} \\
\times 10^{5} \mathrm{~s}^{-1}\end{array}$ & $\begin{array}{c}k_{I S C,} \\
\times 10^{8} \mathrm{~s}^{-1}\end{array}$ & $\begin{array}{l}k_{r I S C}{ }^{a}{ }^{2} \\
\times 10^{7} \mathrm{~s}^{-1}\end{array}$ & $\begin{array}{c}k_{r}, \mathrm{~b} \\
\times 10^{5} \mathrm{~s}^{-} \\
1\end{array}$ & $\begin{array}{c}k_{n r}, \\
\times 10^{5} \mathrm{~s}^{-1}\end{array}$ & $\begin{array}{c}\tau, \mu \mathrm{s} \\
(77 \mathrm{~K})\end{array}$ \\
\hline 1 & 472 & 0.86 & $\begin{array}{c}6 \\
(0.2 \%)\end{array}$ & $\begin{array}{c}2.50 \\
(45.4 \%)\end{array}$ & $\begin{array}{c}10.59 \\
(54.4 \%)\end{array}$ & 2.88 & 1.56 & 0.44 & 1.67 & 2.56 & 1.25 & 0.20 & $\begin{array}{c}6.3(\mathrm{CT}) ;^{\mathrm{b}} \\
3500\left({ }^{3} \mathrm{LE}\right)\end{array}$ \\
\hline 2 & 488 & 0.90 & $\begin{array}{c}10 \\
(0.4 \%)\end{array}$ & $\begin{array}{c}2.04 \\
(46.6 \%)\end{array}$ & $\begin{array}{c}8.30 \\
(53.0 \%)\end{array}$ & 3.95 & 2.06 & 0.57 & 0.99 & 1.47 & 1.68 & 0.19 & $\begin{array}{c}5.6(\mathrm{CT}) \mathrm{b}^{\mathrm{b}} \\
3400\left({ }^{3} \mathrm{LE}\right)\end{array}$ \\
\hline 3 & 482 & 0.84 & $\begin{array}{c}12 \\
(0.4 \%)\end{array}$ & $\begin{array}{c}1.50 \\
(61.6 \%)\end{array}$ & $\begin{array}{c}5.20 \\
(38.0 \%)\end{array}$ & 2.70 & 3.45 & 0.61 & 0.83 & 1.91 & 2.89 & 0.55 & $\begin{array}{c}4.5(\mathrm{CT}){ }^{\mathrm{b}}{ }^{6} \\
3100\left({ }^{3} \mathrm{LE}\right)\end{array}$ \\
\hline 4 & 492 & 0.84 & $\begin{array}{c}19 \\
(0.8 \%)\end{array}$ & $\begin{array}{c}1.43 \\
(59.8 \%)\end{array}$ & $\begin{array}{c}4.25 \\
(39.4 \%)\end{array}$ & 3.44 & 3.52 & 0.78 & 0.52 & 1.21 & 3.32 & 0.63 & $\begin{array}{c}4.2(\mathrm{CT}))^{b} \\
2900\left({ }^{3} \mathrm{LE}\right)\end{array}$ \\
\hline
\end{tabular}

For all compounds PL decays of PMMA film samples (Fig. 5b) can be fitted with triexponential functions (Table 1). The fastest decay component in the 6-18 ns range is attributed to the prompt fluorescence. While the contribution of this low-lifetime emission 
towards the total PL intensity is quite small $(0.2-0.8 \%)$, it still can be well resolved, in comparison to other emissive TADF-active $\mathrm{Cu}$ complexes, where the rapid ISC process leads to a complete excitation transfer to the triplet states. ${ }^{18}$ For $\mathbf{1}-\mathbf{4}$ the ISC is limited by the small SOC between $S_{1}$ and $T_{1}$ levels. By applying conventional PL kinetics equations used for allorganic TADF emitters, ${ }^{44}$ we estimate the ISC rate of the complexes ( $\mathrm{k}_{\mathrm{ISC}}$ ) to vary in the range $5.22-16.66 \times 10^{7} \mathrm{~s}^{-1}$, about two orders of magnitude higher than the radiative rate from the $\mathrm{S}_{1}$ state (Table 1). Delayed emission decays over several $\mu$ s and consists of two components with a comparable contribution to total PL intensity: one with 1.43-2.50 $\mu$ s and other with 4.25-10.59 $\mu$ s lifetime. The overall radiative rate of the complexes varies in the interval $\mathrm{k}_{\mathrm{r}}$ $=1.25-3.32 \times 10^{5} \mathrm{~s}^{-1}$. An increase by a factor of 2 in $\mathrm{k}_{\mathrm{r}}$ is evident for MeCbz-functionalized compounds 3 and 4. As discussed previously, this observation can be related to the higher oscillator strength values for the lower energy CT states of these compounds.
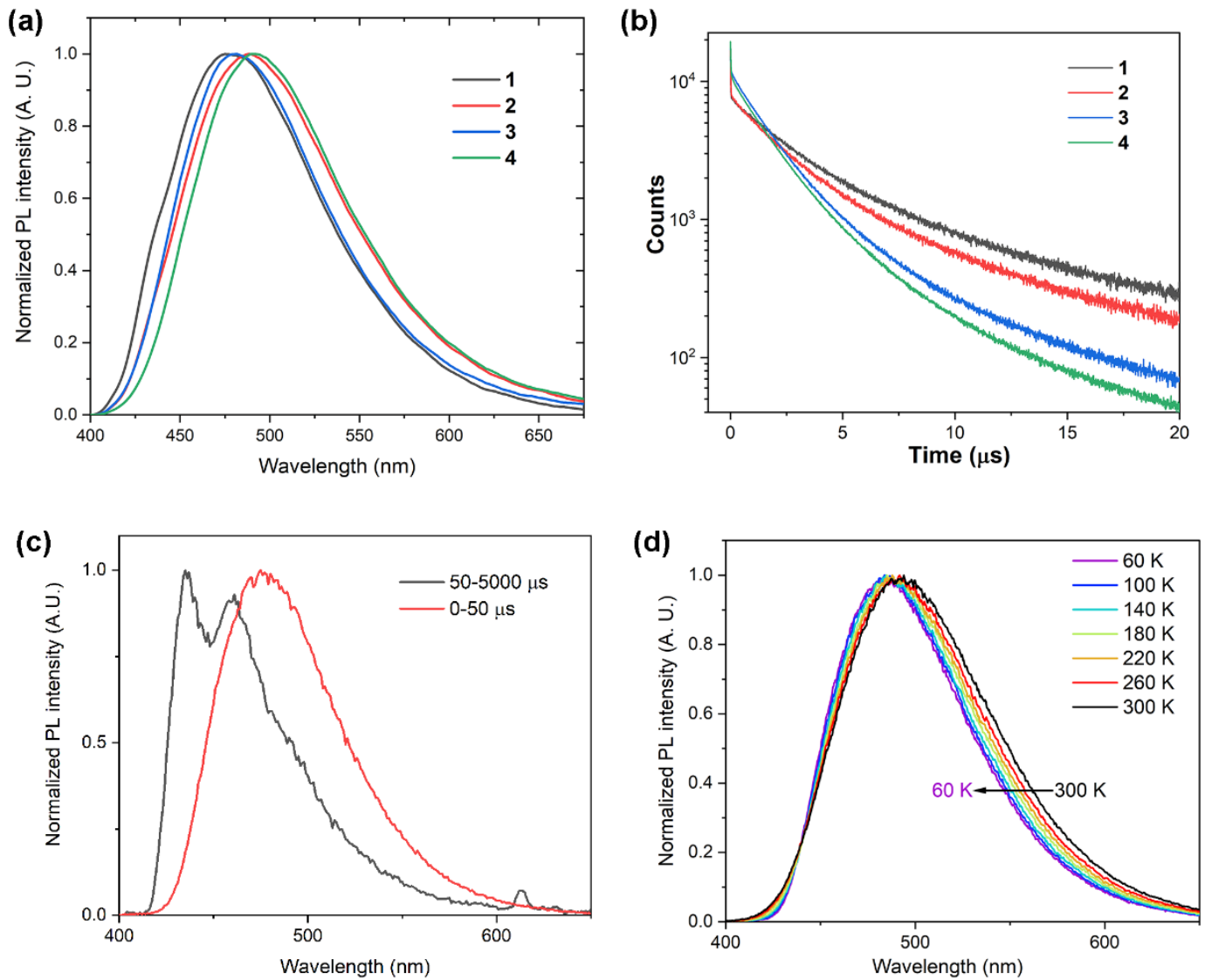

Figure 5. PL characteristics of PMMA-doped complexes 1-4 (5 wt\% emitter content). (a) PL bands. (b) PL decays. (c) PL bands of 4 measured at $77 \mathrm{~K}$ temperature. Time-resolved emission measurements show CT emission (red) and LE phosphorescence (blue). (d) Temperatureinduced CT emission band shifts for 4 obtained with time-resolved measurements in 0-50 $\mu \mathrm{s}$ time window after the excitation. 
Time resolved PL measurements at $77 \mathrm{~K}$ reveal that at low temperature conditions CT emission is being accompanied by long-lived ${ }^{3} \mathrm{LE}$ phosphorescence of the carbazolide ligands (Fig. 5c, S10). A similar effect has been observed for other CMAs and is related to the destabilizing effects of the solvation shell in the frozen host matrix, which raises ${ }^{1} \mathrm{CT}$ close to or above ${ }^{3}$ LE level. ${ }^{17,36}$ In conformity with this assumption, the temperature scans show a gradual cooling-induced blueshift of the CT bands (Fig. 5d). Interestingly, while Cbz and $\mathrm{MeCbz}$ donor fragments show identical phosphorescence spectra in the pure form, in the complexed state the shapes and spectral placement of the ${ }^{3} \mathrm{LE}$ phosphorescence bands exhibit pronounced differences (Fig. S11). This disparity is attributed to the overcrowding-induced change in hybridization of the $\mathrm{N}$ atom in MeCbz ligand. In addition, ${ }^{3} \mathrm{LE}$ level in $\mathbf{3}$ and $\mathbf{4}$ is slightly destabilized and lays $0.04 \mathrm{eV}$ higher, in theory providing a tool for energy level tuning.

To gain an understanding about the delayed emission mechanism of the complexes, PL kinetics were investigated in 10-300 K temperature range (Table S7). Compounds 2 and 4 were characterized to assess the impact of carbazolide ligand structure. The intensity of CT emission gradually decreases with the cooling, revealing a behavior that is more in line with all-organic than heavy metal-promoted TADF emitters. In the absence of strong SOC, the emission from ${ }^{3} \mathrm{CT}$ states proceeds at timescale that cannot compete with the nonradiative vibrational relaxation. This means that for such emitters PL intensity drops at low temperatures, as the lack of thermal activation traps the excitation in the dark triplet state. ${ }^{1}$ For TADF-active $\mathrm{Cu}$ complexes the situation is different. The moderate SOC values promote efficient ${ }^{3} \mathrm{CT}$ phosphorescence with typical lifetimes of few hundred $\mu$ s, and PL intensity remains practically constant, as with the temperature decrease the dominating emission mechanism gradually shifts from TADF to phosphorescence. ${ }^{33}$ The behavior of 1-4 belongs to the former case. This assumption is additionally supported by TD-DFT calculations, which estimate phosphorescence lifetime from $\mathrm{T}_{1}$ state of 1 to be $0.22 \mathrm{~s}$, too long for this to be a viable emissive pathway. A slight deviation from the beforementioned trend is observed for complex $\mathbf{4}$, for which the maximal PL efficiency is measured at $220 \mathrm{~K}\left(\Phi_{\mathrm{PL}}=0.93\right)$. This is attributed to the cooling induced solidification of the host matrix and consequent suppression of emissionquenching torsional motions.

Throughout the explored temperature interval, the compounds retain triexponential decay curves, featuring a prompt and two delayed emission components (Fig. 6a,b; Table S7). The temperature-induced changes in emission rate constants for the two long-lived PL constituents provide another direct evidence for TADF process (Fig. 6c,d). For both, the fastest 
$\left(\mathrm{TADF}_{1}\right)$ and slowest $\left(\mathrm{TADF}_{2}\right)$ delayed emission components a gradual radiative emission rate $\left(k_{r_{T A D F}}\right)$ decrease is observed throughout the cooling range, designating a thermally activated nature of the emissive process. In contrast, the prompt PL component does not exhibit a rate decrease. The corresponding $\Delta \mathrm{E}_{\mathrm{ST}}$ values were estimated from the fits of Arrhenius plots relating temperature and the experimental $k_{r_{T A D F}}$ values (Fig. 6e,f). ${ }^{18}$ For the all examined emissive processes highly similar activation energies were obtained, in the range of $0.0062-0.0075 \mathrm{eV}$. These values correspond well with the TD-DFT predictions for the energy gaps between $\mathrm{T}_{1}$ and $\mathrm{S}_{1}$ levels of the carbazolide-to-Dipp related CT states. 

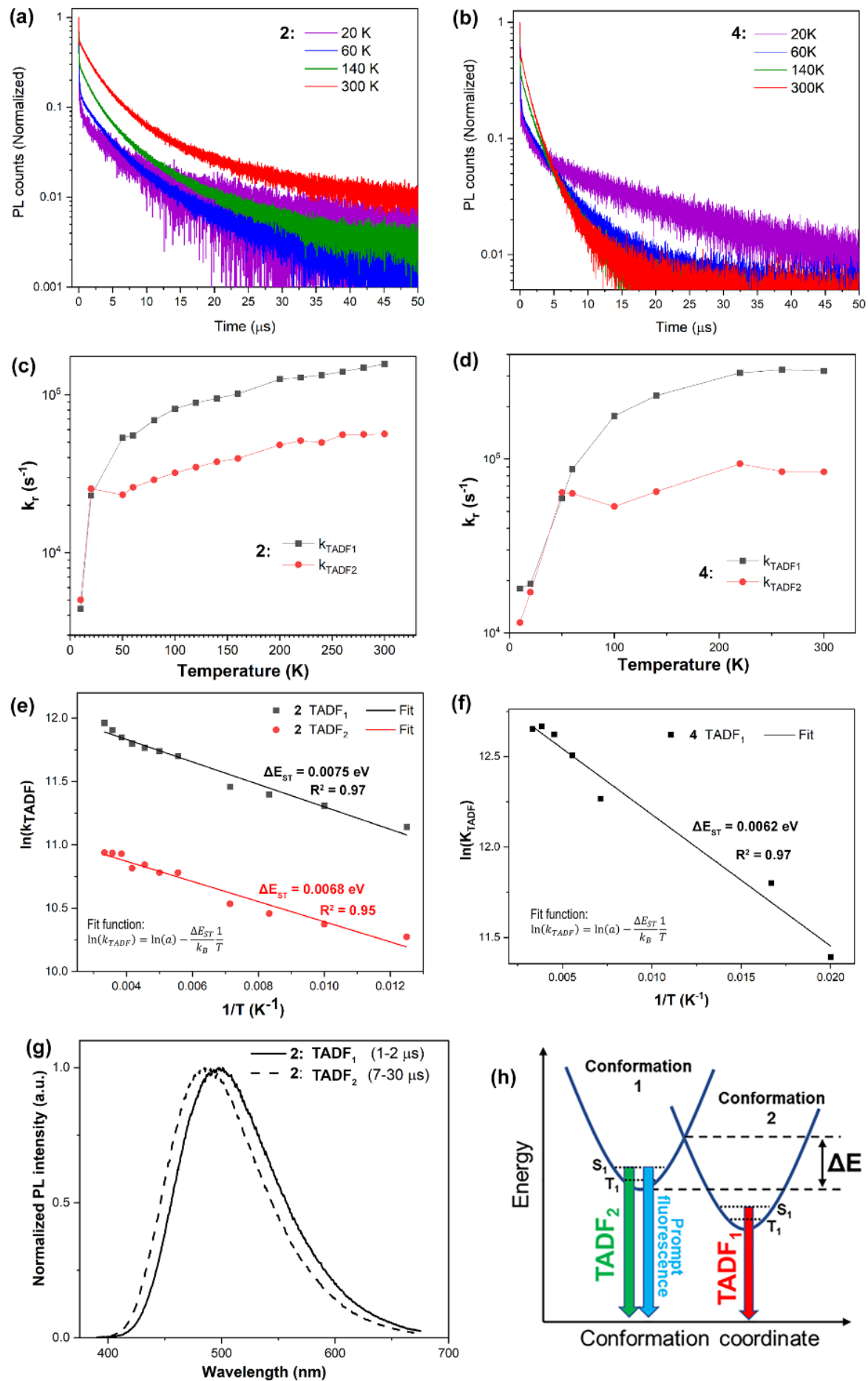

Figure 6. PL decay at selected temperatures for 2 (a) and 4 (b). Temperature dependence of delayed emission component rates for 2 (c) and 4 (d). Arrhenius plots (circles) showing the correlation between $\mathrm{k}_{\mathrm{TADF}}$ and temperature for $\mathbf{2}$ (e) and 4 (f). Fit function formula, corresponding fits (lines) and obtained $\Delta \mathrm{E}_{\text {ST }}$ values are shown. Time resolved PL spectra of 2 measured at room temperature $(\mathrm{g})$. Emission collected at 1-2 $\mu$ s interval shows predominantly $\mathrm{TADF}_{1}$, while $7-30 \mu$ s interval is dominated by $\mathrm{TADF}_{2}$. The proposed mechanism for dual delayed emission (h). 
To explain the origin of two distinct TADF processes for 1-4, time-resolved PL spectra were obtained by collecting PL intensities in $\mathrm{TADF}_{1}$ dominated $(1-2 \mu \mathrm{s})$ and $\mathrm{TADF}_{2}(7-30 \mu \mathrm{s})$ dominated time intervals (Fig. 6g, S12). Except for complex 4, where PL bands of TADF 1 and $\mathrm{TADF}_{2}$ almost overlap, $\mathrm{TADF}_{2}$ is blueshifted in relation to $\mathrm{TADF}_{1}$. This is an opposite behavior to many triplet emitters, where longer lived emissive states usually attain lower energies due to the progressive exciton migration to lower energy states. ${ }^{45}$ Additionally, the ratio of the PL intensities between $\mathrm{TADF}_{1}$ and $\mathrm{TADF}_{2}$ is temperature dependent (Table S7), and below $50 \mathrm{~K}$ the overall $\mathrm{CT}$ emission becomes almost completely dominated by $\mathrm{TADF}_{2}$. The beforementioned observations lets us propose a mechanism for the dual TADF (Fig. 6h), attributing each emissive process to an individual structural conformation of the complex molecule. Upon the photoexcitation primarily the $\mathrm{CT}$ state associated with $\mathrm{TADF}_{2}$ becomes populated and relaxes to the molecular configuration denoted as Conformation 1. In conformity with low-temperature measurements, the following excitation transfer to the Conformation 2 , exhibiting $\mathrm{TADF}_{1}$ emission, is associated with an energetical barrier $(\Delta \mathrm{E})$, even though in the relaxed state it assumes a lower energy than $\mathrm{TADF}_{2}$. The rate $k_{r_{T A D F 1}}$ is by a factor 2 larger than $k_{r_{T A D F 2}}$. As indicated by $\Delta \mathrm{E}_{S T}$ values obtained for $\mathbf{2}$, this cannot be explained by a lower activation energy for $\mathrm{TADF}_{1}$, as, in fact, it is lower for $\mathrm{TADF}_{2}$. Accordingly, the rate difference arises due to a substantial oscillator strength increase for ${ }^{1} \mathrm{CT}$ states associated to the Conformation 2. For through-space CT process this can be induced by arranging the D and A fragments closer to the face-to-face configuration. The consequence for such structural change is a characteristic PL redshift, ${ }^{38,46}$ which, indeed, is observed in the case of TADF 1 emission. In terms of structures $\mathbf{1 - 4}$, this dual emission is thought to be caused by energetic minima that arises due to a possible Renner-Teller distortions, resulting in a decrease in $\mathrm{C} 1-\mathrm{Cu}-\mathrm{N} 2$ angle, ${ }^{37,47}$ or by the pyramidization at carbazolide $\mathrm{N}$ atom, like it is observed in the $\mathrm{X}$-ray structure of complex 4. Both these structural changes would shift the plane of carbazolide ligand in a more coplanar arrangement with Dipp fragments.

In accordance with the proposed emissive mechanism, the prompt fluorescence arises from Conformation 1. By assuming that the same emissive ${ }^{1} \mathrm{CT}$ state is involved in $\mathrm{TADF}_{2}$ process, the corresponding rISC rates for $\mathbf{1}-\mathbf{4}$ are estimated at $1.21-2.56 \times 10^{7} \mathrm{~s}^{-1}$ (Table 1). In conformity with the hybrid nature of the proposed TADF emitter architecture, these values fall in between the conventional metal-promoted designs $\left(\mathrm{k}_{\mathrm{rISC}} \sim 10^{8} \mathrm{~s}^{-1}\right)^{18}$ and state-of-art allorganic through space emitters $\left(\mathrm{k}_{\mathrm{rISC}} \sim 10^{6} \mathrm{~s}^{-1}\right) .{ }^{48,49}$ 
To assess the prospects of the compounds for electroluminescence related applications solution-processed test device were prepared with the architecture ITO/PEDOT:PSS/PolyTPD/4(20wt\%):CzSi/TPBi/LiF/Al. Electroluminescence from CT state of the complex was successfully realized (Fig. S13) showing that the presented molecular design is suitable for a potential OLED use.

\section{Conclusions}

On the basis of structural examples 1-4 we have demonstrated a novel concept to the development of efficient TADF emitters. By combining through-space CT architecture, giving compounds the characteristic low $\Delta \mathrm{E}_{\mathrm{ST}}$ values, with the presence of a heavy metal atom, which provides small, but still present SOC, rISC values exceeding $10^{7} \mathrm{~s}^{-1}$ can be attained. While the examined compounds can still be classified as carbene-metal-amide complexes, from the point of photophysical functionality, the carbene fragment acts as an inert linking fragment between a carbene-bound acceptor and a metal-bound donor. In such way conventional and easy to obtain imidazole-based carbenes can serve as building blocks towards such emitters, in contrast to carbene-to-carbazolide CT state emitters, where a careful tuning of carbene electronic levels is necessary. ${ }^{42}$ Additionally, we demonstrate that a direct metal bonding to only one of the CTconstituting aromatic systems is sufficient to provide a rapid TADF process. Emissive rates in the presented emitters can be substantially increased by ensuring face-to-face alignment between $\mathrm{D}$ and A fragments, what can be achieved through sterical overcrowding-induced twist of the carbazolide plane. The presented findings provide valuable guidelines towards further development of TADF-active molecules.

\section{Associated content}

\section{Supporting information}

Additional figures and tables, formulas used for the calculation of emission kinetics parameters, NMR spectra, cyclic voltammetry curves, atomic coordinates of DFT optimized structures.

\section{Author information}

\section{Corresponding author}

* kaspars.traskovskis@rtu.lv 


\section{Acknowledgments}

This research is funded by Latvian Council of Science, project No. lzp-2019/1-0231. The authors acknowledge Riga Technical University's HPC Center for providing access to their computing infrastructure.

\section{References}

(1) Uoyama, H.; Goushi, K.; Shizu, K.; Nomura, H.; Adachi, C. Highly Efficient Organic Light-Emitting Diodes from Delayed Fluorescence. Nature 2012, 492 (7428), 234238. https://doi.org/10.1038/nature11687.

(2) Yang, Z.; Mao, Z.; Xie, Z.; Zhang, Y.; Liu, S.; Zhao, J.; Xu, J.; Chi, Z.; Aldred, M. P. Recent Advances in Organic Thermally Activated Delayed Fluorescence Materials. Chem. Soc. Rev. 2017, 46 (3), 915-1016. https://doi.org/10.1039/C6CS00368K.

(3) Bryden, M. A.; Zysman-Colman, E. Organic Thermally Activated Delayed Fluorescence (TADF) Compounds Used in Photocatalysis. Chem. Soc. Rev. 2021, 50 (13), 7587-7680. https://doi.org/10.1039/D1CS00198A.

(4) Ni, F.; Li, N.; Zhan, L.; Yang, C. Organic Thermally Activated Delayed Fluorescence Materials for Time-Resolved Luminescence Imaging and Sensing. Adv. Opt. Mater. 2020, 8 (14), 1902187. https://doi.org/10.1002/adom.201902187.

(5) Köhler, A.; Beljonne, D. The Singlet-Triplet Exchange Energy in Conjugated Polymers. Adv. Funct. Mater. 2004, 14 (1), 11-18. https://doi.org/10.1002/adfm.200305032.

(6) Goushi, K.; Adachi, C. Efficient Organic Light-Emitting Diodes through upConversion from Triplet to Singlet Excited States of Exciplexes. Appl. Phys. Lett. 2012, 101 (2), 023306. https://doi.org/10.1063/1.4737006.

(7) Graves, D.; Jankus, V.; Dias, F. B.; Monkman, A. Photophysical Investigation of the Thermally Activated Delayed Emission from Films of M-MTDATA:PBD Exciplex. Adv. Funct. Mater. 2014, 24 (16), 2343-2351. https://doi.org/10.1002/adfm.201303389.

(8) Kim, K.-H.; Yoo, S.-J.; Kim, J.-J. Boosting Triplet Harvest by Reducing Nonradiative Transition of Exciplex toward Fluorescent Organic Light-Emitting Diodes with 100\% Internal Quantum Efficiency. Chem. Mater. 2016, 28 (6), 1936-1941. https://doi.org/10.1021/acs.chemmater.6b00478.

(9) Shao, S.; Hu, J.; Wang, X.; Wang, L.; Jing, X.; Wang, F. Blue Thermally Activated 
Delayed Fluorescence Polymers with Nonconjugated Backbone and Through-Space Charge Transfer Effect. J. Am. Chem. Soc. 2017, 139 (49), 17739-17742.

https://doi.org/10.1021/jacs.7b10257.

(10) Tsujimoto, H.; Ha, D.-G.; Markopoulos, G.; Chae, H. S.; Baldo, M. A.; Swager, T. M. Thermally Activated Delayed Fluorescence and Aggregation Induced Emission with Through-Space Charge Transfer. J. Am. Chem. Soc. 2017, 139 (13), 4894-4900. https://doi.org/10.1021/jacs.7b00873.

(11) Li, J.; Shen, P.; Zhao, Z.; Tang, B. Z. Through-Space Conjugation: A Thriving Alternative for Optoelectronic Materials. CCS Chem. 2019, 1 (2), 181-196. https://doi.org/10.31635/ccschem.019.20180020.

(12) Etherington, M. K.; Gibson, J.; Higginbotham, H. F.; Penfold, T. J.; Monkman, A. P. Revealing the Spin-Vibronic Coupling Mechanism of Thermally Activated Delayed Fluorescence. Nat. Commun. 2016, 7 (1), 13680. https://doi.org/10.1038/ncomms 13680.

(13) Wang, Y.; Huang, C.; Ye, H.; Zhong, C.; Khan, A.; Yang, S.; Fung, M.; Jiang, Z.; Adachi, C.; Liao, L. Through Space Charge Transfer for Efficient Sky-Blue Thermally Activated Delayed Fluorescence (TADF) Emitter with Unconjugated Connection. $A d v$. Opt. Mater. 2020, 8 (2), 1901150. https://doi.org/10.1002/adom.201901150.

(14) Ma, Y.; Che, C.-M.; Chao, H.-Y.; Zhou, X.; Chan, W.-H.; Shen, J. High Luminescence Gold(I) and Copper(I) Complexes with a Triplet Excited State for Use in LightEmitting Diodes. Adv. Mater. 1999, 11 (10), 852-857. https://doi.org/10.1002/(SICI)1521-4095(199907)11:10<852::AIDADMA852>3.0.CO;2-R.

(15) Harkins, S. B.; Peters, J. C. A Highly Emissive Cu 2 N 2 Diamond Core Complex Supported by a [PNP] - Ligand. J. Am. Chem. Soc. 2005, 127 (7), 2030-2031. https://doi.org/10.1021/ja043092r.

(16) Di, D.; Romanov, A. S.; Yang, L.; Richter, J. M.; Rivett, J. P. H.; Jones, S.; Thomas, T. H.; Abdi Jalebi, M.; Friend, R. H.; Linnolahti, M.; Bochmann, M.; Credgington, D. High-Performance Light-Emitting Diodes Based on Carbene-Metal-Amides. Science (80-. ). 2017, 356 (6334), 159-163. https://doi.org/10.1126/science.aah4345.

(17) Hamze, R.; Peltier, J. L.; Sylvinson, D.; Jung, M.; Cardenas, J.; Haiges, R.; Soleilhavoup, M.; Jazzar, R.; Djurovich, P. I.; Bertrand, G.; Thompson, M. E. Eliminating Nonradiative Decay in Cu(I) Emitters: \&gt;99\% Quantum Efficiency and Microsecond Lifetime. Science (80-. ). 2019, 363 (6427), 601-606. 
https://doi.org/10.1126/science.aav2865.

(18) Hamze, R.; Shi, S.; Kapper, S. C.; Muthiah Ravinson, D. S.; Estergreen, L.; Jung, M.C.; Tadle, A. C.; Haiges, R.; Djurovich, P. I.; Peltier, J. L.; Jazzar, R.; Bertrand, G.; Bradforth, S. E.; Thompson, M. E. "Quick-Silver” from a Systematic Study of Highly Luminescent, Two-Coordinate, d 10 Coinage Metal Complexes. J. Am. Chem. Soc. 2019, 141 (21), 8616-8626. https://doi.org/10.1021/jacs.9b03657.

(19) Thompson, M. E.; Li, T. Y.; Djurovich, P.; Shlian, D. A Luminescent Two-Coordinate $\mathrm{Au}(\mathrm{I})$ Bimetallic Complex with a Tandem-Carbene Structure: A Molecular Design for the Enhancement of TADF Radiative Decay Rate. Chem. - A Eur. J. 2021, chem.202100512. https://doi.org/10.1002/chem.202100512.

(20) Leuthäußer, S.; Schwarz, D.; Plenio, H. Tuning the Electronic Properties of NHeterocyclic Carbenes. Chem. - A Eur. J. 2007, 13 (25), 7195-7203. https://doi.org/10.1002/chem.200700228.

(21) Bedford, R. B.; Betham, M. N -H Carbazole Synthesis from 2-Chloroanilines via Consecutive Amination and C-H Activation. J. Org. Chem. 2006, 71 (25), 9403-9410. https://doi.org/10.1021/jo061749g.

(22) Sheldrick, G. M. SHELXT - Integrated Space-Group and Crystal-Structure Determination. Acta Crystallogr. Sect. A Found. Adv. 2015, 71 (1), 3-8. https://doi.org/10.1107/S2053273314026370.

(23) Sheldrick, G. M. A Short History of SHELX. Acta Crystallogr. Sect. A Found. Crystallogr. 2008, 64 (1), 112-122. https://doi.org/10.1107/S0108767307043930.

(24) Dolomanov, O. V.; Bourhis, L. J.; Gildea, R. J.; Howard, J. A. K.; Puschmann, H. OLEX2 : A Complete Structure Solution, Refinement and Analysis Program. J. Appl. Crystallogr. 2009, 42 (2), 339-341. https://doi.org/10.1107/S0021889808042726.

(25) Bochevarov, A. D.; Harder, E.; Hughes, T. F.; Greenwood, J. R.; Braden, D. A.; Philipp, D. M.; Rinaldo, D.; Halls, M. D.; Zhang, J.; Friesner, R. A. Jaguar: A Highperformance Quantum Chemistry Software Program with Strengths in Life and Materials Sciences. Int. J. Quantum Chem. 2013, 113 (18), 2110-2142. https://doi.org/10.1002/qua.24481.

(26) Yu, H. S.; He, X.; Li, S. L.; Truhlar, D. G. MN15: A Kohn-Sham Global-Hybrid Exchange-Correlation Density Functional with Broad Accuracy for Multi-Reference and Single-Reference Systems and Noncovalent Interactions. Chem. Sci. 2016, 7 (8), 5032-5051. https://doi.org/10.1039/C6SC00705H.

(27) Zhang, H. Q.; Jin, Y.; Qiu, Y. The Optical and Electrical Characteristics of PMMA 
Film Prepared by Spin Coating Method. IOP Conf. Ser. Mater. Sci. Eng. 2015, 87, 012032. https://doi.org/10.1088/1757-899X/87/1/012032.

(28) Lu, T.; Chen, F. Multiwfn: A Multifunctional Wavefunction Analyzer. J. Comput. Chem. 2012, 33 (5), 580-592. https://doi.org/10.1002/jcc.22885.

(29) te Velde, G.; Bickelhaupt, F. M.; Baerends, E. J.; Fonseca Guerra, C.; van Gisbergen, S. J. A.; Snijders, J. G.; Ziegler, T. Chemistry with ADF. J. Comput. Chem. 2001, 22 (9), 931-967. https://doi.org/10.1002/jcc.1056.

(30) Li, J.; Wang, L.; Zhao, Z.; Li, X.; Yu, X.; Huo, P.; Jin, Q.; Liu, Z.; Bian, Z.; Huang, C. Two-Coordinate Copper(I)/NHC Complexes: Dual Emission Properties and Ultralong Room-Temperature Phosphorescence. Angew. Chemie Int. Ed. 2020, 59 (21), 8210 8217. https://doi.org/10.1002/anie.201916379.

(31) Tzouras, N. V.; Martynova, E. A.; Ma, X.; Scattolin, T.; Hupp, B.; Busen, H.; Saab, M.; Zhang, Z.; Falivene, L.; Pisanò, G.; Van Hecke, K.; Cavallo, L.; Cazin, C. S. J.; Steffen, A.; Nolan, S. P. Simple Synthetic Routes to Carbene-M-Amido (M=Cu, Ag, $\mathrm{Au}$ ) Complexes for Luminescence and Photocatalysis Applications. Chem. - A Eur. J. 2021, 27 (46), 11904-11911. https://doi.org/10.1002/chem.202101476.

(32) Shi, S.; Jung, M. C.; Coburn, C.; Tadle, A.; Sylvinson M. R., D.; Djurovich, P. I.; Forrest, S. R.; Thompson, M. E. Highly Efficient Photo- and Electroluminescence from Two-Coordinate $\mathrm{Cu}(\mathrm{I})$ Complexes Featuring Nonconventional N-Heterocyclic Carbenes. J. Am. Chem. Soc. 2019, 141 (8), 3576-3588. https://doi.org/10.1021/jacs.8b12397.

(33) Leitl, M. J.; Zink, D. M.; Schinabeck, A.; Baumann, T.; Volz, D.; Yersin, H. Copper(I) Complexes for Thermally Activated Delayed Fluorescence: From Photophysical to Device Properties. Top. Curr. Chem. 2016, 374 (3), 25. https://doi.org/10.1007/s41061-016-0019-1.

(34) Leiva, A. M.; Rivera, L.; Loeb, B. Analysis of Copper(I) Stability in the Cationic $[\mathrm{Cu}(\mathrm{CH} 3 \mathrm{CN}) 4-\mathrm{n}(\mathrm{Ph} 3 \mathrm{P}) \mathrm{n}]+$ Series of Complexes. Polyhedron 1991, 10 (3), 347-350. https://doi.org/10.1016/S0277-5387(00)80155-2.

(35) Chotard, F.; Sivchik, V.; Linnolahti, M.; Bochmann, M.; Romanov, A. S. Monoversus Bicyclic Carbene Metal Amide Photoemitters: Which Design Leads to the Best Performance? Chem. Mater. 2020, 32 (14), 6114-6122. https://doi.org/10.1021/acs.chemmater.0c01769.

(36) Romanov, A. S.; Jones, S. T. E.; Gu, Q.; Conaghan, P. J.; Drummond, B. H.; Feng, J.; Chotard, F.; Buizza, L.; Foley, M.; Linnolahti, M.; Credgington, D.; Bochmann, M. 
Carbene Metal Amide Photoemitters: Tailoring Conformationally Flexible Amides for Full Color Range Emissions Including White-Emitting OLED. Chem. Sci. 2020, 11 (2), 435-446. https://doi.org/10.1039/C9SC04589A.

(37) Lin, S.; Ou, Q.; Wang, Y.; Peng, Q.; Shuai, Z. Aggregation-Enhanced Thermally Activated Delayed Fluorescence Efficiency for Two-Coordinate Carbene-MetalAmide Complexes: A QM/MM Study. J. Phys. Chem. Lett. 2021, 12 (11), 2944-2953. https://doi.org/10.1021/acs.jpclett.1c00020.

(38) Li, Q.; Hu, J.; Lv, J.; Wang, X.; Shao, S.; Wang, L.; Jing, X.; Wang, F. Through-Space Charge-Transfer Polynorbornenes with Fixed and Controllable Spatial Alignment of Donor and Acceptor for High-Efficiency Blue Thermally Activated Delayed Fluorescence. Angew. Chemie Int. Ed. 2020, 59 (45), 20174-20182. https://doi.org/10.1002/anie.202008912.

(39) Eng, J.; Thompson, S.; Goodwin, H.; Credgington, D.; Penfold, T. J. Competition between the Heavy Atom Effect and Vibronic Coupling in Donor-Bridge-Acceptor Organometallics. Phys. Chem. Chem. Phys. 2020, 22 (8), 4659-4667. https://doi.org/10.1039/C9CP06999B.

(40) Samanta, P. K.; Kim, D.; Coropceanu, V.; Brédas, J.-L. Up-Conversion Intersystem Crossing Rates in Organic Emitters for Thermally Activated Delayed Fluorescence: Impact of the Nature of Singlet vs Triplet Excited States. J. Am. Chem. Soc. 2017, 139 (11), 4042-4051. https://doi.org/10.1021/jacs.6b12124.

(41) Lüdtke, N.; Föller, J.; Marian, C. M. Understanding the Luminescence Properties of $\mathrm{Cu}(<\mathrm{scp}>\mathrm{i}</ \mathrm{Scp}>)$ Complexes: A Quantum Chemical Perusal. Phys. Chem. Chem. Phys. 2020, 22 (41), 23530-23544. https://doi.org/10.1039/D0CP04654J.

(42) Gernert, M.; Balles-Wolf, L.; Kerner, F.; Müller, U.; Schmiedel, A.; Holzapfel, M.; Marian, C. M.; Pflaum, J.; Lambert, C.; Steffen, A. Cyclic (Amino)(Aryl)Carbenes Enter the Field of Chromophore Ligands: Expanded $\pi$ System Leads to Unusually Deep Red Emitting Cu I Compounds. J. Am. Chem. Soc. 2020, 142 (19), 8897-8909. https://doi.org/10.1021/jacs.0c02234.

(43) Wang, X.; Wang, S.; Lv, J.; Shao, S.; Wang, L.; Jing, X.; Wang, F. Through-Space Charge Transfer Hexaarylbenzene Dendrimers with Thermally Activated Delayed Fluorescence and Aggregation-Induced Emission for Efficient Solution-Processed OLEDs. Chem. Sci. 2019, 10 (10), 2915-2923. https://doi.org/10.1039/C8SC04991B.

(44) Dias, F. B.; Penfold, T. J.; Monkman, A. P. Photophysics of Thermally Activated Delayed Fluorescence Molecules. Methods Appl. Fluoresc. 2017, 5 (1), 012001. 
https://doi.org/10.1088/2050-6120/aa537e.

(45) Mikhnenko, O. V.; Blom, P. W. M.; Nguyen, T.-Q. Exciton Diffusion in Organic Semiconductors. Energy Environ. Sci. 2015, 8 (7), 1867-1888.

https://doi.org/10.1039/C5EE00925A.

(46) Moon, C.-K.; Huh, J.-S.; Kim, J.-M.; Kim, J.-J. Electronic Structure and Emission Process of Excited Charge Transfer States in Solids. Chem. Mater. 2018, 30 (16), 5648-5654. https://doi.org/10.1021/acs.chemmater.8b02011.

(47) Taffet, E. J.; Olivier, Y.; Lam, F.; Beljonne, D.; Scholes, G. D. Carbene-Metal-Amide Bond Deformation, Rather Than Ligand Rotation, Drives Delayed Fluorescence. $J$. Phys. Chem. Lett. 2018, 9 (7), 1620-1626. https://doi.org/10.1021/acs.jpclett.8b00503.

(48) Huang, T.; Wang, Q.; Xiao, S.; Zhang, D.; Zhang, Y.; Yin, C.; Yang, D.; Ma, D.; Wang, Z.; Duan, L. Simultaneously Enhanced Reverse Intersystem Crossing and Radiative Decay in Thermally Activated Delayed Fluorophors with Multiple Throughspace Charge Transfers. Angew. Chemie Int. Ed. 2021. https://doi.org/10.1002/anie.202109041.

(49) Wu, C.; Liu, W.; Li, K.; Cheng, G.; Xiong, J.; Teng, T.; Che, C.; Yang, C. Face-toFace Orientation of Quasiplanar Donor and Acceptor Enables Highly Efficient Intramolecular Exciplex Fluorescence. Angew. Chemie Int. Ed. 2021, 60 (8), 39943998. https://doi.org/10.1002/anie.202013051. 